\title{
Synergistic Action of a Metalloprotease and a Serine Protease from Fusarium oxysporum f. sp. Iycopersici Cleaves Chitin-Binding Tomato Chitinases, Reduces Their Antifungal Activity, and Enhances Fungal Virulence
}

\author{
Mansoor Karimi Jashni, ${ }^{1,2}$ Ivo H. M. Dols, ${ }^{1}$ Yuichiro lida, ${ }^{1,3}$ Sjef Boeren, ${ }^{4}$ Henriek G. Beenen, ${ }^{1}$ \\ Rahim Mehrabi, ${ }^{1}$ Jérôme Collemare, ${ }^{1}$ and Pierre J. G. M. de Wit ${ }^{1}$ \\ ${ }^{1}$ Laboratory of Phytopathology, Wageningen University and Research Centre, 6708 PB, Wageningen, The Netherlands; \\ ${ }^{2}$ Department of Plant Pathology, Tarbiat Modares University, 14115-336, Tehran, Iran; ${ }^{3}$ National Agriculture and Food \\ Research Organization, 514-2392, Tsu, Mie, Japan; ${ }^{4}$ Laboratory of Biochemistry, Wageningen University, 6703 HA, \\ Wageningen, The Netherlands
}

Submitted 10 April 2015. Accepted 22 April 2015.

\begin{abstract}
As part of their defense strategy against fungal pathogens, plants secrete chitinases that degrade chitin, the major structural component of fungal cell walls. Some fungi are not sensitive to plant chitinases because they secrete chitin-binding effector proteins that protect their cell wall against these enzymes. However, it is not known how fungal pathogens that lack chitinbinding effectors overcome this plant defense barrier. Here, we investigated the ability of fungal tomato pathogens to cleave chitin-binding domain (CBD)-containing chitinases and its effect on fungal virulence. Four tomato CBD chitinases were produced in Pichia pastoris and were incubated with secreted proteins isolated from seven fungal tomato pathogens. Of these, Fusarium oxysporum f. sp. lycopersici, Verticillium dahliae, and Botrytis cinerea were able to cleave the extracellular tomato chitinases SIChi1 and SIChi13. Cleavage by $F$. oxysporum removed the CBD from the N-terminus, shown by mass spectrometry, and significantly reduced the chitinase and antifungal activity of both chitinases. Both secreted metalloprotease FoMep1 and serine protease FoSep1 were responsible for this cleavage. Double deletion mutants of FoMep1 and FoSep1 of F. oxysporum lacked chitinase cleavage activity on SIChi1 and SIChi13 and showed reduced virulence on tomato. These results demonstrate the importance of plant chitinase cleavage in fungal virulence.
\end{abstract}

Upon recognition of general elicitors, plants induce basal defenses that confer resistance to a wide range of pathogens. An important component of these defenses is the accumulation of pathogenesis-related (PR) proteins (Sels et al. 2008). Indeed, PR proteins have low or no expression in healthy plants, but their expression is strongly induced upon infection by various

Current address of R. Mehrabi: Department of Wheat Breeding, Seed and Plant Improvement Institute, 33181-31359, Karaj, Iran.

Current address of J. Collemare: UMR1345, IRHS-INRA, 49071 Beaucouzé, France.

Corresponding author: P. J. G. M. de Wit: E-mail: Pierre.deWit@wur.nl

*The $\boldsymbol{e}$-Xtra logo stands for "electronic extra" and indicates that 20 supplementary figures and six supplementary tables are published online.

(c) 2015 The American Phytopathological Society plant pathogens (Godoy et al. 1996; Joosten and De Wit 1989). Many PR proteins show antifungal activities, with a major role for those that exhibit $\beta$-1,3-glucanase and chitinase activities (Cota et al. 2007; Sinha et al. 2014). Both types of enzymes act synergistically to inhibit the growth of many fungi (Jongedijk et al. 1995; Mauch et al. 1988; Sela-Buurlage et al. 1993) through the hydrolysis of $\beta$-1,3-glucans and chitin $(\beta$-1,4-linked $N$-acetylglucosamine), which are major structural components of fungal cell walls (Balasubramanian et al. 2012; Grover 2012). Hydrolysis of $\beta$-1,3-glucans and chitin leads to thinning of hyphal tips, followed by swelling and, eventually, bursting (Arlorio et al. 1992). Antifungal activity of chitinases has been exploited to improve broad-spectrum resistance of plants. For example, plants such as tobacco, tomato, potato, peanut, and cacao engineered to overexpress chitinases show enhanced resistance to fungal pathogens (Cletus et al. 2013; Dana et al. 2006; Iqbal et al. 2012; Maximova et al. 2006; Schickler and Chet 1997).

Based on a primary amino acid sequence of the catalytic domain, chitinases are grouped into two glycosyl hydrolase $(\mathrm{GH})$ families, GH18 or 19 GH19. The GH19 family is largely composed of plant chitinases GH19, while GH18 are found throughout the tree of life (Grover 2012; Hamid et al. 2013; Li and Greene 2010). Based on their amino acid sequence similarity, GH18 chitinases are divided into two structural classes, III and V (Ohnuma et al. 2011), and GH19 chitinases into four classes, I, II, IV, and VII (Ohnuma et al. 2012). Class I and class IV chitinases are distinct in sequence, but they all contain a chitin-binding domain (CBD), which is absent in class II and class VII chitinases ( $\mathrm{Lu}$ et al. 2003). Binding of the CBD to chitin was reported to increase the enzymatic efficiency of CBD chitinases and, expectedly, removal of the CBD diminishes their antifungal activity (Iseli et al. 1993; Suarez et al. 2001). All plant chitinases harbor a signal peptide to enter the secretory pathway. In addition, class I chitinases contain a C-terminal vacuolar localization signature that directs them to the vacuole (Neuhaus et al. 1991; Wubben et al. 1992). Other chitinases are extracellular, residing in the plant apoplast (Neuhaus et al. 1991).

The role of chitinases in plant-fungal pathogen interactions has been well studied for the interaction between tomato (Solanum lycopersicum) and the leaf mold pathogen Cladosporium fulvum. This fungus is strictly extracellular and colonizes the apoplastic space between the mesophyll cells of tomato leaves (de Wit et al. 2012). Although it has been reported that infection by C. fulvum 
induces the synthesis of tomato chitinases in the apoplast (Joosten and De Wit 1989), this fungus is not sensitive to plant chitinases (Joosten et al. 1995). It was suggested that this is due to secretion of the chitin-binding effector protein CfAvr4, which binds to the chitin in the cell wall of $C$. fulvum (van den Burg et al. 2006). Indeed, CfAvr4 was shown to bind chitin in the cell wall of Trichoderma viride and Fusarium solani f. sp. phaseoli and to protect them against the hydrolytic activity of plant chitinases (van den Burg et al. 2006). Functional homologs of CfAvr4 were identified in other Dothideomycete plant pathogens, in which they also likely protect cell walls against plant chitinases (de Wit et al. 2012; Stergiopoulos et al. 2010). Noteworthy, vascular and necrotrophic tomato pathogens like Fusarium oxysporum $\mathrm{f}$. sp. lycopersici $(F$. oxysporum), Verticillium dahliae, F. solani f. sp. phaseoli, Botrytis cinerea, and Alternaria spp. do not have a homolog of the CfAvr4 gene in their genomes. Among these pathogens, $F$. solani $\mathrm{f}$. sp. phaseoli was shown to be sensitive to chitinases (van den Burg et al. 2006; van Esse et al. 2007). Although these fungal pathogens lack a functional Avr4 homolog, they still overcome the deleterious effects of chitinases during plant infection. The fact that these fungal pathogens could overcome the resistance of plants overexpressing chitinases suggests that they employ mechanisms to compromise the deleterious effects of plant chitinases. Previously, proteolytic processing of a class IV chitinase during infection of bean roots by $F$. solani $\mathrm{f}$. sp. phaseoli (Lange et al. 1996) and in vitro proteolytic processing of a tobacco vacuolar class I chitinase by culture filtrate of the same fungus were reported (Sela-Buurlage 1996). Also, an extracellular protease from $F$. solani $\mathrm{f}$. sp. eumartii was shown to degrade PR proteins from the intercellular washing fluids of potato (Olivieri et al. 2002). More recently, it was shown that $F$. verticillioides and other maize pathogens, including Bipolaris zeicola and Stenocarpella maydis, secrete proteins that truncate maize class IV chitinases (Naumann 2011; Naumann and Wicklow 2010; Naumann et al. 2009). Altogether, these data strongly suggest that some fungal pathogens may inactivate induced host chitinases and possibly other PR proteins by proteolytic cleavage.
In the present study, we address the hypothesis that fungal pathogens lacking chitin-binding CfAvr4 homologs secrete proteases to cleave plant chitinases to overcome their deleterious effects. To this aim, we investigated the cleavage activity on antifungal CBD chitinases of the model crop tomato by several of its fungal pathogens. We report the expression of tomato CBD chitinases during infection by $C$. fulvum and $F$. oxysporum as representatives of an extracellular foliar (carrying CfAvr4) and a vascular tomato pathogen (lacking a CfAvr4 homolog), respectively. We assessed the proteolytic activity of these two species and five additional tomato pathogens on four CBD chitinases produced in $P$. pastoris. We show that three fungal tomato pathogens secrete proteases that cleave two of the four extracellular CBD chitinases, resulting in complete or partial removal of the CBD and reduction of their antifungal activity. Finally, we identified the secreted proteases in F. oxysporum that are responsible for the cleavage of CBD chitinases and showed that they play an important role in virulence of this fungus.

\section{RESULTS}

The tomato genome contains 30 genes that encode predicted chitinases grouped in seven different classes.

To study the molecular interaction between tomato chitinases and fungal proteases that might cleave them, we first set out to determine the full complement of genes encoding putative chitinases in the tomato genome. Tblastn searches with characterized plant chitinases from the six reported classes retrieved a total of 30 genes, named SlChil to SlChi30, of which 23 were predicted to encode complete and functional proteins (Fig. 1; Supplementary Fig. S1; Supplementary Table S1).

Chromosomal location analysis showed that genes encoding chitinases of a given class were often located on the same chromosome, which did not carry genes encoding a chitinase from another class. Noteworthy, genes encoding chitinases from the same class were frequently organized in clusters comprising both functional and nonfunctional genes (Supplementary Fig. S2). This

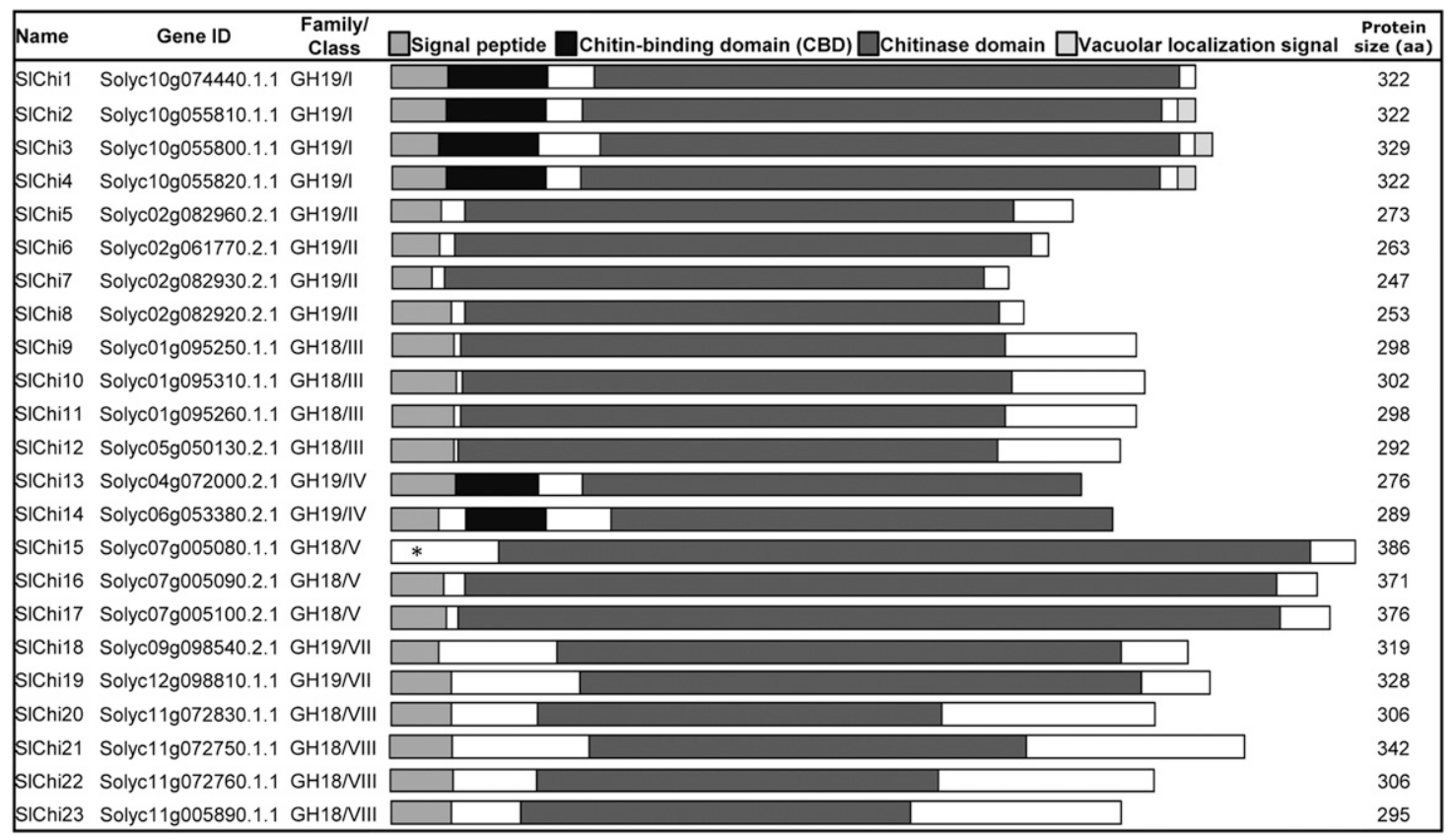

Fig. 1. Characteristics of predicted functional chitinases from tomato. The tblastn search of the tomato genome identified 23 genes that encode likely functional chitinases, named S1Chi1 to S1Chi23. The family and class of each predicted chitinase is indicated, based on sequence similarity and presence of glycosyl hydrolase conserved domains. Their protein structure is represented on scale. An asterisk indicates the absence of a signal peptide in SlChi15, indicating that it is unclear whether this predicted chitinase is functional or not. SlChil lacks a vacuolar localization signal and, thus, might be extracellular. 
observation suggests frequent gene duplication events, which might indicate a role in coevolution with fungal pathogens. Twenty-six predicted tomato chitinases were grouped into the six described classes, based on sequence similarity, protein structure, and phylogenetic analysis (Supplementary Figs. S3 through $\mathrm{S} 12)$. The four remaining predicted GH18 chitinases were related to TBC-2 from Tulipa species and were previously assigned as a class IIIb chitinase (Yamagami and Ishiguro 1998) (Fig. 1). However, their sequences did not seem to be related to chitinases from class III, and therefore, we propose to assign these chitinases as well as TBC-2 to a new class, VIII. In addition, two chitinases from Picea species that were reported to belong to class VII (Kolosova et al. 2014) lack two conserved regions compared with class VII chitinases and share high sequence similarity to class IV chitinases throughout the entire chitinase domain. A phylogenetic analysis of GH19 chitinases also showed that Picea chitinases belong to a monophyletic clade that comprises class IV chitinases only (Supplementary Fig. S13). Therefore, we propose they are members of class IV chitinases that lost the CBD independently from class II chitinases. Furthermore, the GH19 chitinase phylogenetic tree also shows that class I and class II share a common origin, indicating a single loss event of the CBD for these two families.

Of 30 chitinase genes in tomato, a number that is comparable to the 25 chitinase genes in Arabidopsis thaliana and 49 chitinase genes in rice (Oryza sativa) (Grover 2012), six encode CBD chitinases (four class I and two class IV genes). Because of the presumed importance of the $\mathrm{CBD}$ for enzymatic and antifungal activities of chitinases (Iseli et al. 1993; Suarez et al. 2001) and because of the reported CBD cleavage by fungal proteases, these six genes represent good candidates that might play a role in defense of tomato against fungal pathogens and were selected for further analyses.

\section{Induction of CBD chitinase genes in tomato after inoculation with $C$. fulvum and $F$. oxysporum suggests a role in plant defense.}

Previously, it was found that expression of SlChi2 is induced when tomato plants are challenged with the protective strain Fo47 (Aimé et al. 2013) or a pathogenic strain of $F$. oxysporum (Houterman et al. 2007). In addition, SlChi2, SlChi6, SlChi7, and SlChi8 were up-regulated upon infection by C. fulvum (Danhash et al. 1993; Joosten and De Wit 1989). We hypothesized that tomato extracellular and vacuolar CBD chitinases might be differentially regulated in response to the attack by fungal pathogens with different infection styles. To test this hypothesis, susceptible tomato cultivar MM-Cf-0 was inoculated with the foliar pathogen $C$. fulvum and the vascular pathogen $F$. oxysporum. Expression profiles of the six genes encoding CBD chitinases were analyzed using real time quantitative reverse transcription-polymerase chain reaction. All six genes exhibited a low basal expression level at 0 days postinoculation (dpi) in both leaves and roots (Fig. 2). None of them were induced during early infection (0 to $6 \mathrm{dpi}$ ) by $C$. fulvum, but SlChi2, SlChi3, and SlChi4 were all significantly up-regulated at a late stage of infection (12 dpi). SlChi2 was significantly induced from 8 dpi onwards (Fig. 2A), which corresponds to massive colonization of the apoplast by C. fulvum (de Wit et al. 2012). All three induced genes encode predicted vacuole-localized class I chitinases that are expected to become active after release into the extracellular space at later time points of infection when vacuoles collapse. Mass spectrometry analysis of apoplastic fluids obtained from tomato leaves $12 \mathrm{dpi}$ with $C$. fulvum revealed the

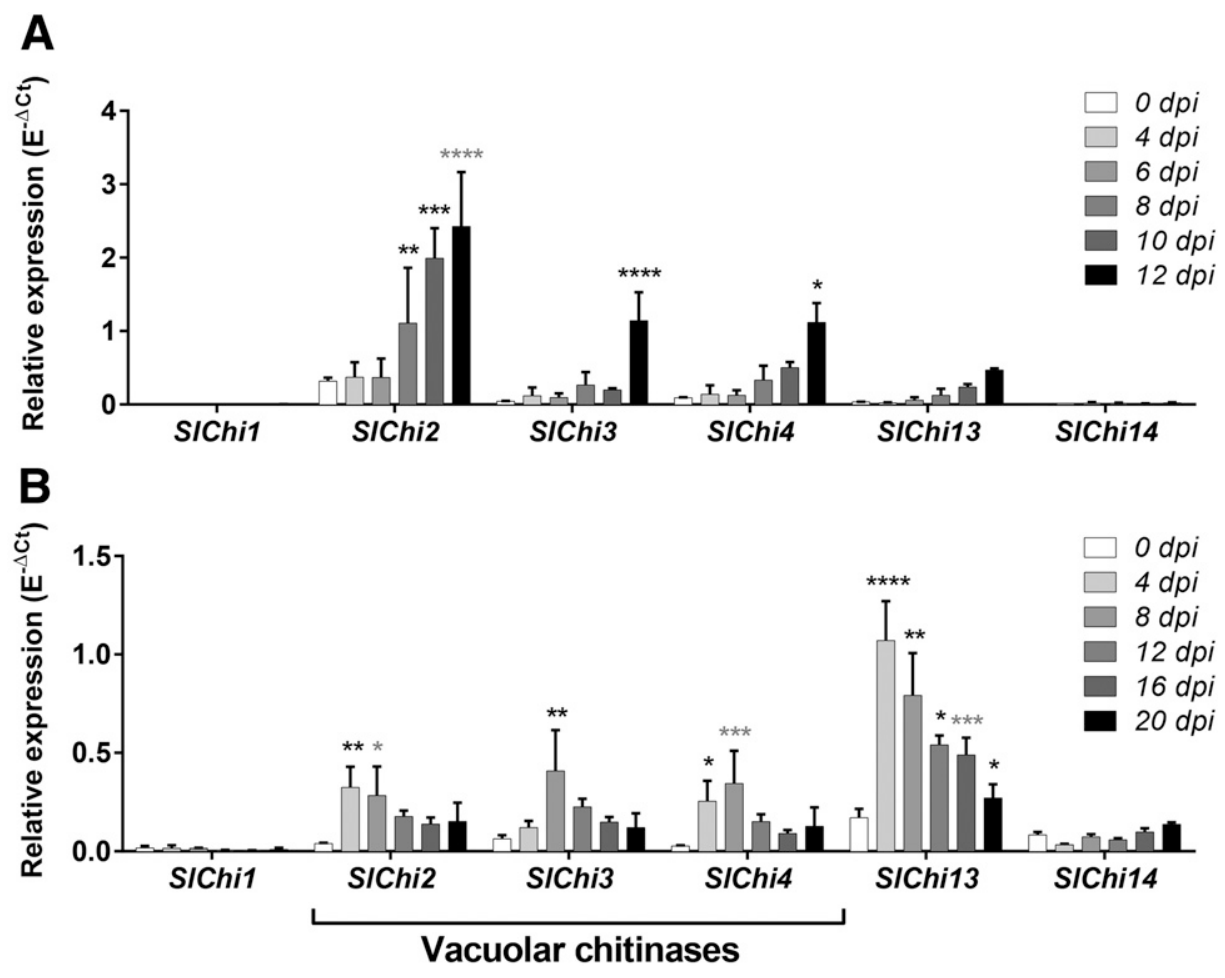

Fig. 2. Expression of tomato genes encoding chitin-binding domain (CBD)-containing chitinases is induced upon fungal infection. A, Susceptible tomato cultivar Money-Maker Cf-0 was inoculated with Cladosporium fulvum or B, Fusarium oxysporum f. sp. lycopersici (F. oxysporum). Leaf samples of C. fulvum-inoculated plants, and root samples of F. oxysporum-inoculated plants were collected at different days postinoculation (dpi) for RNA extraction and subsequent real time quantitative reverse transcription-polymerase chain reaction. Expression of CBD-chitinase genes is normalized to that of the tomato $\beta$-tubulin gene $(L e T u b)$ using the $\mathrm{E}^{-\Delta \mathrm{Ct}}$ method (Livak and Schmittgen 2001). The bars show the average of three biological replications with standard deviation. A two-way analysis of variance with a posthoc Tukey's multiple comparisons test was performed. Black asterisks indicate significant differential expression compared with the previous time point. When not applicable, gray asterisks indicate significant differential expression compared with 0 dpi (* indicates $P$ value $<0.5$; **, $P$ value $<0.01$; ***, $P$ value $<0.001$; and ****, $P$ value $<0.0001$ ). 
presence of the CBD chitinase proteins SlChi1, SIChi2, S1Chi3, and S1Chi13. In contrast, in roots inoculated with F. oxysporum, the predicted extracellular chitinase SlChil3 was highly induced from 4 dpi onwards (Fig. 2B) and, thereafter, its expression decreased gradually to reach, at $20 \mathrm{dpi}$, the same expression level as at $0 \mathrm{dpi}$. In addition, the vacuolar chitinases SlChi3 and SlChi4 were transiently up-regulated at 8 dpi only and to a lower extent than SiChi13. Altogether, these results showed that SlChi3 and SlChi4 were slightly and transiently upregulated in both leaves and roots in response to fungal infection, suggesting a minor role in tomato defense. SlChi2 and SlChil3 were highly up-regulated in response to infection by $C$. fulvum and F. oxysporum, respectively. These two chitinases might provide a higher level of protection in response to fungal pathogens with different infection strategies.

Three fungal pathogens of tomato secrete proteins that cleave extracellular CBD chitinases, which reduces their chitinase activity.

It has previously been shown that fungi secrete proteases that cleave CBD chitinases (Olivieri et al. 2002; Sela-Buurlage 1996).
Chitinase-modifying assays with pure maize CBD chitinase and a metalloprotease from $F$. verticillioides (Naumann et al. 2011) showed the truncation of this chitinase and determined the cleavage site. To assess whether tomato fungal pathogens also exhibit such activity, we performed a similar chitinase-modifying assay. For this purpose, seven tomato fungal pathogens with different infection strategies, including C. fulvum, Alternaria solani, Alternaria arborescens, B. cinerea (foliar pathogens), V. dahliae, $F$. oxysporum, and $F$. solani (vascular pathogens), were grown on autoclaved tomato leaves and their secreted proteins were isolated. The six CBD chitinases of tomato were expressed in P. pastoris, but only SlChi1, SlChi2, SlChi4, and SlChi13 could be produced and purified in sufficient amounts. These four CBD chitinases were incubated for $20 \mathrm{~h}$ with secreted protein extracts from the seven fungal tomato pathogens, and their possible cleavage was analyzed by sodium dodecyl sulfate-polyacrylamide gel electrophoresis (SDS-PAGE). None of the secreted protein extracts could cleave the vacuolar CBD chitinases SlChi2 and SlChi4, including extracts from $C$. fulvum (Fig. 3A). However, a slight increase in electrophoretic mobility was observed for SlChi4 after incubation with extract from $B$. cinerea, suggesting that this fungus
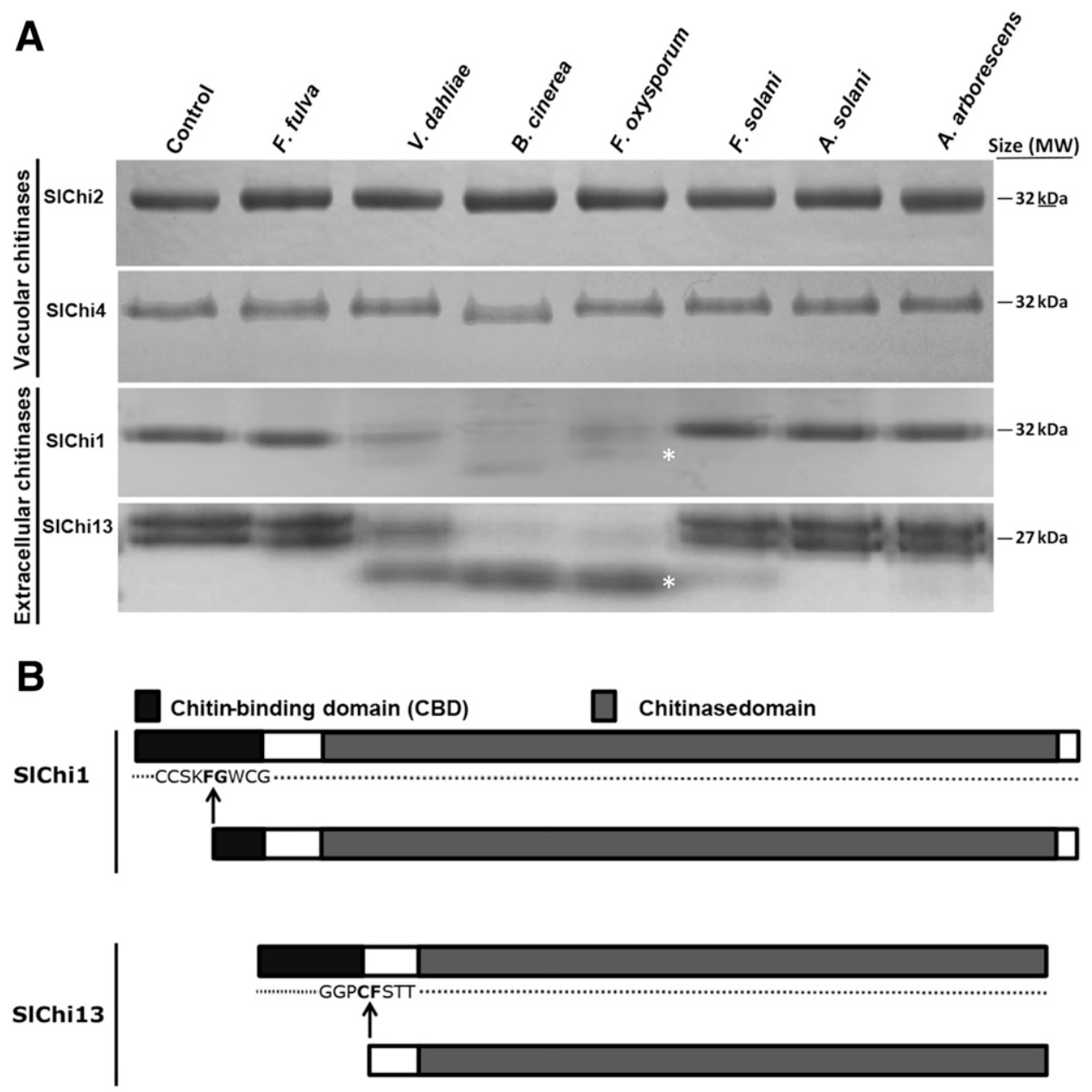

Fig. 3. Secreted protein extracts from fungal pathogens remove the chitin-binding domain (CBD) of extracellular tomato chitinases. A, The four tomato CBD chitinases SlChi1, SlChi2, SlChi4, and SlChi13 were produced by Pichia pastoris. Pure chitinases were incubated for $20 \mathrm{~h}$ with secreted protein extracts isolated from the tomato pathogens Cladosporium fulvum, Verticillium dahliae, Botrytis cinerea, Fusarium oxysporum f. sp. lycopersici ( $F$. oxysporum), Fusarium solani f. sp. phaseoli (F. solani), Alternaria solani, and Alternaria arborescens. Results of the in vitro reactions were visualized on Coomassie bluestained sodium dodecyl sulfate-polyacrylamide electrophoresis gels. Control is pure chitinase incubated in $10 \mathrm{mM}$ sodium acetate buffer (pH 5.2) for $20 \mathrm{~h}$. The white asterisks indicate cleaved products of SlChil and SlChi13 that were isolated for mass spectrometry analysis. Chitinase modifying assays were performed at least three times. B, Cleaved products of SIChi1 and SlChi13 after incubation with protein extract from F. oxysporum were sequenced by mass spectrometry to determine the cleavage sites. The cleavage site for SIChi1 is located within the CBD and the cleavage site for SlChil3 is located at the beginning of the hinge between the CBD and the chitinase catalytic domain. For each chitinase, the upper bar represents the mature chitinase and the lower bar represents the cleaved chitinase. Arrows indicate the cleavage sites located between the two bold amino acid residues. 
might cleave this CBD chitinase. In contrast, secreted protein extracts from $F$. oxysporum, $V$. dahliae, and $B$. cinerea clearly modified the two extracellular CBD chitinases SIChil and SlChi13 into forms that migrated faster on the SDS-PAGE gels, indicating that they were cleaved (Fig. 3A). Extract from $F$. solani also appeared to cleave SlChi13, albeit to a lesser extent. Secreted protein extracts from C. fulvum,

\section{A}

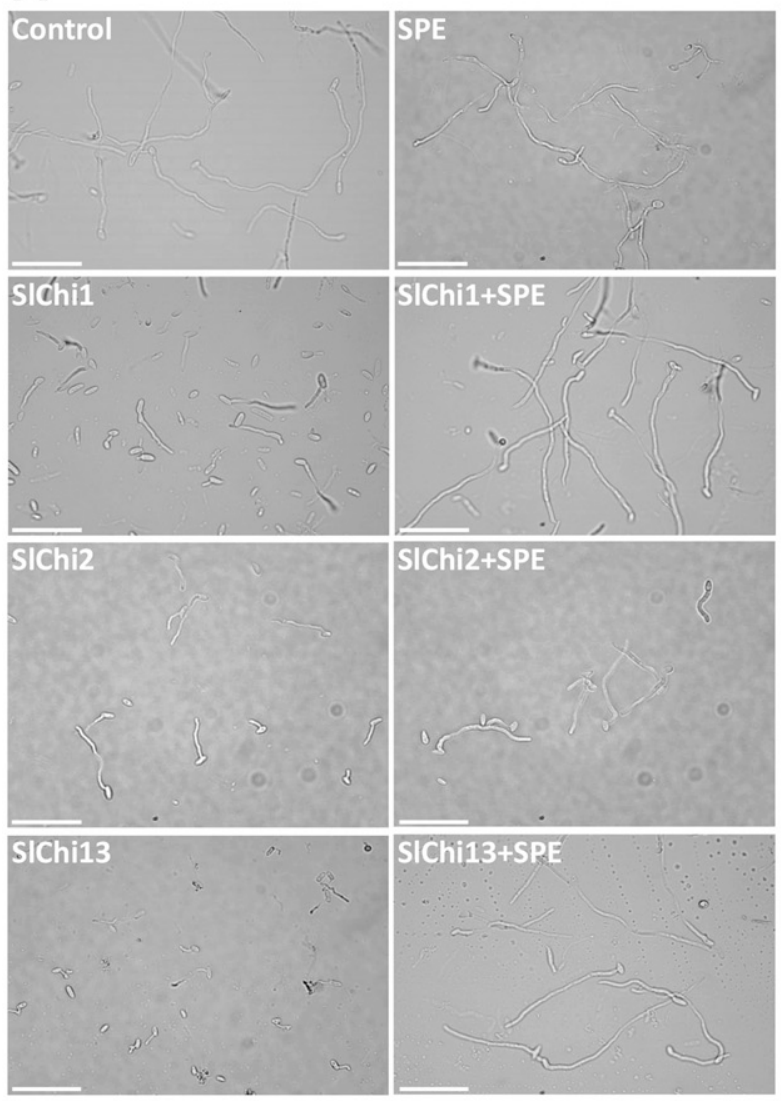

B

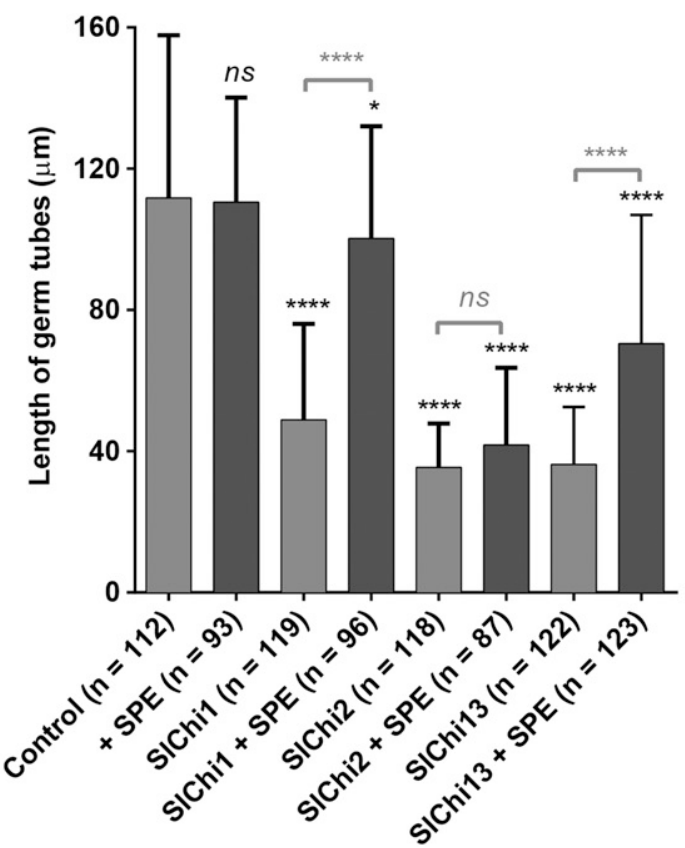

A. solani, and A. arborescens did not cleave the extracellular CBD chitinases.

To determine the N-termini of the SlChil and SlChi13 products cleaved by the $F$. oxysporum extract, they were excised from the SDS-PAGE gel and were analyzed by liquid chromatography/tandem mass spectrometry (LC-MS/MS). Mass spectrometric analysis showed full coverage of the C-termini of both cleaved SlChil and SlChi13. No peptide covered the first 37 amino acids at the N-terminus of S1Chi1, while native SlChil was fully covered. The potential cleavage site is located in the middle of the CBD, and the removed upstream sequence includes two cysteine residues that are predicted to form disulfide bonds with two other cysteine residues behind the cleavage site (Fig. 3B; Supplementary Fig. S14). Such cleavage likely results in a nonfunctional CBD. Mass spectrometry analysis of the cleaved product of SIChi13 showed that no peptide covered the first 49 amino acids at the N-terminus (Fig. 3B; Supplementary Fig. S15). The potential cleavage site is located at the beginning of the hinge between the CBD and catalytic domain, resulting in complete removal of the CBD. These results suggest that $F$. oxysporum removes CBDs from extracellular CBD chitinases that might affect their chitinase and antifungal activity.

\section{Removal of the CBD from SIChi1 and SIChi13 reduces their chitinase and antifungal activity.}

We assayed the chitinase activity of intact CBD chitinases and chitinases that had lost their CBD after incubation with protein extracts from $F$. oxysporum. Loss of the CBD of SlChil and SlChi13 significantly reduced the chitinase activity, using insoluble chitin azure as a substrate (Supplementary Fig. S16). Chitinase activity of SlChi2, of which the CBD is not removed by protein extracts from $F$. oxysporum remained unchanged, stressing the importance of the CBD for chitinase activity on insoluble chitin. Antifungal activity of SlChi1 and SlChi13 was also significantly reduced after cleavage of the CBD by secreted protein extracts from $F$. oxysporum. Native SlChi1, SlChi2, and SlChi13 significantly inhibited the growth of germ tubes of $F$. oxysporum when compared with the controls (buffer and secreted protein extracts) (Fig. 4A). The average length of germ tubes was reduced by 32 to $44 \%$ after incubation with SlChi1, SlChi2, and SlChi13 (Fig. 4B). Mixing SlChil and SlChi13 CBD chitinases with secreted protein extracts from $F$. oxysporum prior to incubation with fungal spores resulted in significant reduction of growth inhibition as shown by longer germ tubes (Fig. 4). These results demonstrate that removal of the CBD from SlChi1 and SlChi13 by $F$. oxysporum leads to a significant reduction of their chitinase activity and antifungal activity against this fungus. In contrast, no significant difference in growth inhibition was observed for germ tubes incubated with SlChi2 that was either treated or not treated with secreted protein extract from $F$. oxysporum.

Fig. 4. Cleavage of tomato chitin-binding domain-containing chitinases reduces their antifungal activity against Fusarium oxysporum f. sp. lycopersici. A, Representative pictures of $F$. oxysporum f. sp. lycopersici (F. oxysporum) germinating spores that were incubated for $16 \mathrm{~h}$ in $10 \mathrm{mM}$ sodium acetate buffer ( $\mathrm{pH}$ 5.2) alone or buffer containing $10 \mu \mathrm{g}$ of secreted protein extract (SPE) isolated from in vitro-grown F. oxysporum as controls. Germinating spores were also incubated with intact or cleaved SIChi1, SlChi2, and SlChi13 chitinases. Scale bars indicate $50 \mu \mathrm{m}$ in size. B, Average length and standard deviation of germ tubes after treatments shown in A. Number of measured germ tubes is indicated on parentheses. A one-way analysis of variance with a posthoc Tukey's multiple comparisons test was performed. Black asterisks indicate significant differences in length of germ tubes compared with control, and gray asterisks indicate significant differences between intact and cleaved chitinases. (* indicates $P$ value $<0.5$; $* * * *, P$ value $<0.0001)$ 


\section{Deletion of the fungalysin metalloprotease FoMep1} partly reduces chitinase cleavage activity of $F$. oxysporum.

The fungalysin metalloprotease encoded by the gene FVEG_13630.0 of $F$. verticillioides was shown to cleave maize chitinases (Naumann et al. 2011). A likely ortholog of this gene with $95.41 \%$ nucleic acid identity is present in the genome of F. oxysporum (FOXG_16612), which we named FoMep1. Presence of FoMep1 in xylem sap extracted from MM-Cf-0 tomato infected by $F$. oxysporum was revealed by mass spectrometry analysis (Supplementary Fig. S17). Therefore, we hypothesized that this metalloprotease might be responsible for cleavage of SlChi1 or SlChi13 or both. Three targeted deletion mutants were obtained in which a cassette carrying the hygromycin-resistance and green fluorescent protein (GFP) genes replaced FoMep1. All three $\Delta$ fomepl deletion mutants did not show any in vitro phenotype different from wild type and ectopic transformants. As previously described, secreted protein extracts were isolated from the three $\Delta$ fomepl deletion mutants, wild type, and the ectopic transformant strain for incubation with SlChi1 and SlChi13. The chitinase-modifying assay showed that all protein extracts exhibited the same chitinase cleavage activity on SIChi1 but lost part of their activity on SlChi13 (Fig. 5A). This result indicates that the fungalysin metalloprotease encoded by FoMepl is required for partial modification of class IV CBD chitinase SlChi13 but not for class I CBD chitinase S1Chi1.

In order to determine the type of protease that is responsible for additional chitinase-modifying activity in the $\Delta$ fomepl deletion mutants, secreted protein extracts in culture filtrates from these mutants were treated with inhibitors that are specific for cysteine proteases (E64 and cystatin), serine proteases (phenylmethylsulfonyl fluoride [PMSF]), metalloproteases (EDTA), and aspartic proteases (PepA). The chitinase-modifying assay showed that cleavage of SIChi1 and SlChi13 is inhibited by PMSF only at a concentration of $1 \mathrm{mM}$ and higher (Fig. 5B; Supplementary Fig. S18). This result indicates that serine proteases are likely responsible for additional cleavage of tomato CBD chitinases.

\section{Deletion of the serine protease FoSep1 reduces chitinase cleavage activity of $F$. oxysporum $\Delta$ fomep1 deletion mutants.}

Identification of serine protease candidates was performed by fractionating secreted protein extracts from culture filtrates of the $\Delta$ fomepl deletion mutant and testing each fraction for chitinasemodifying activity. The culture filtrates were size-fractionated on a Superdex G-75 column, fractions were incubated with chitinase, and chitinase-modifying activity was monitored by PAGE. Protein bands present in active fractions were cut from the gel and were analyzed by mass spectrometry. Two subtilisin serine proteases (FOXG_09801 and FOXG_01145) were identified in fractions 3 and 4 with chitinase-modifying activity (Supplementary Fig. S19, bands marked with asterisk). Hereafter, the genes are named FoSepl and FoSep2. Deletion mutants, in which a cassette carrying geneticin or hygromycin-resistance and GFP genes replaced the FoSepl and FoSep 2 genes, were generated in both wild-type (single mutants) and $\Delta$ fomepl deletion mutant (double mutants) strains (Supplementary Fig. S20). In addition, both FoSep1 and FoSep2 were deleted in the wild-type background. All single and double mutants showed normal vegetative growth and conidiation in vitro when compared with the wild type and ectopic transformants. As previously described, secreted proteins were isolated from each single and double mutant and were tested in chitinase-modifying assays. The results showed that $\Delta$ fosepl and $\Delta$ fosep 2 single deletion mutants retained full activity against both chitinases SlChil and SlChi13 (Fig. 5C). However, protein extracts from the $\triangle$ ffomepl:: fosepl double mutant appeared to have lost chitinase cleavage activity toward both SlChi1 and SlChi13 almost completely (Fig. 5C).
The $\Delta$ fomep $1::$ fosep 2 and $\Delta \Delta$ fosep1::fosep 2 double mutants showed the same activity as the $\Delta$ fomepl single mutant and the wild-type strain, respectively, indicating that FoSep2 does not display chitinase cleavage activity. Altogether, these results suggest that cleavage of both SlChi1 and SlChi13 chitinases is achieved by synergistic action of the fungalysin metalloprotease FoMep1 and serine protease FoSep1. Furthermore, we could show that chitinase activity of SIChi1 and SlChi13 treated with secreted protein extract of $\Delta \backslash$ fosep $1: \because$ fosep 2 mutant of $F$. oxysporum was not reduced and its antifungal activity was not affected.

\section{A chitinase-modifying metalloprotease and a serine protease are required} for full virulence of $\boldsymbol{F}$. oxysporum on tomato.

To determine the role of FoMepl and FoSepl in virulence, roots of MM-Cf-0 tomato seedling were inoculated with independent
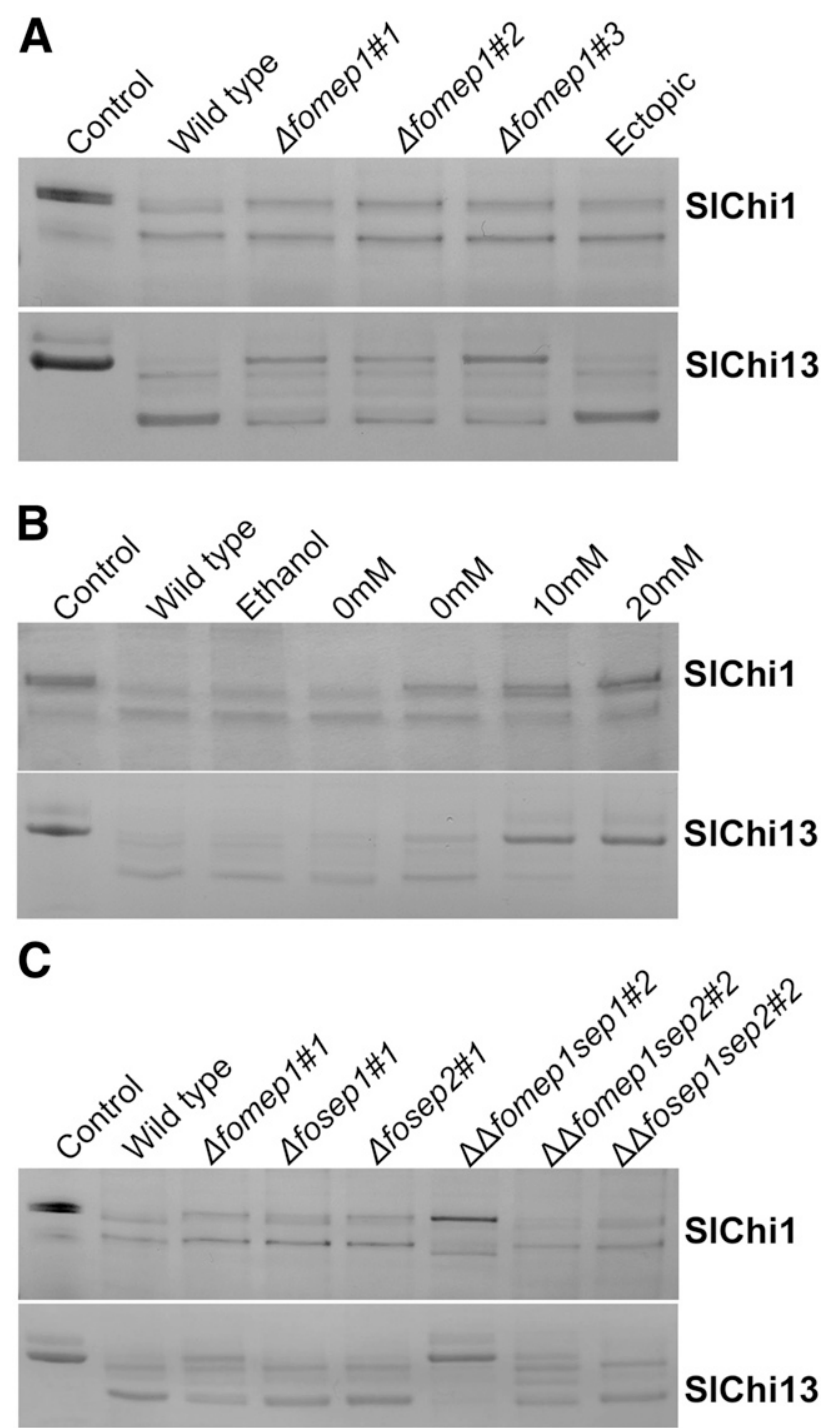

Fig. 5. Synergistic action of a serine protease and metalloprotease from Fusarium oxysporum f. sp. lycopersici ( $F$. oxysporum) cleaves tomato chitin-binding domain-containing chitinases. A, S1Chil and S1Chi13 are cleaved after incubation with secreted protein extracts (SPE) isolated from three independent $F$. oxysporum fungalysin metalloprotease $\Delta$ fomepl deletion mutants. Control is $10 \mathrm{mM}$ sodium acetate buffer ( $\mathrm{pH} \mathrm{5.2).} \mathrm{B,} \mathrm{The}$ serine protease inhibitor phenylmethylsulfonyl fluoride inhibits the cleavage of SIChi1 and S1Chi13 by SPE from the F. oxysporum $\Delta$ fomepl deletion mutants in a concentration-dependent manner. C, Only SPE from $F$. oxysporum double-mutant $\Delta \Delta$ fomepl::fosepl was not able to cleave SlChil and SlChi13. 
single and double deletion mutants of FoMepland FoSepl. Virulence was quantified at 4 weeks postinoculation by measuring the height and fresh weight of the upper part of plants and by scoring the disease index. Results show that the plants inoculated with the single mutants $\Delta$ fomepl and $\Delta$ fosepl performed slightly better growth than plants inoculated with the wild type and ectopic transformants (Fig. 6A and B), although this reduction of virulence is not correlated with a lower disease index (Fig. 6C). Plants inoculated with the double mutants $\Delta \Delta$ fomepl::fosepl were as high as mock-inoculated plants (Fig. $6 \mathrm{~A})$ and were significantly less diseased compared with those inoculated with the wild type and ectopic transformants (Fig. $6 \mathrm{~B}$ and $\mathrm{C}$ ). Altogether, these results indicate that synergistic action of FoMepl and FoSepl is required for full virulence of F. oxysporum on tomato.

\section{DISCUSSION}

Induction and accumulation of PR proteins constitute an important component of basal defense of plants against pathogens (Sels et al. 2008; van Loon et al. 2006; Wu et al. 2014). Several PR proteins are chitinases and $\beta$-1,3-glucanases that have antimicrobial activity especially against fungi that contain chitin and $\beta$-1,3-glucans in their cell walls. CBD-containing chitinases have been reported to show high antifungal activity (Iseli et al. 1993; Suarez et al. 2001; Truong et al. 2003). We analyzed the tomato genome and identified six CBD chitinase-encoding genes corresponding to class I (SlChil, SlChi2, SlChi3, and SlChi4) or class IV chitinases (SlChil3 and SlChi14). They all showed a basic level of expression in healthy tomato plants but a clear differential expression after inoculation with the extracellular leaf pathogen $C$. fulvum and the vascular pathogen $F$. oxysporum. Strong induction of the CBD chitinase SlChi2 at late stages of infection by C. fulvum was shown both at the transcriptome and proteome level. SlChi2 is predicted to localize in the vacuole, but we detected significant levels in the apoplast, which suggests it is either actively secreted or leaking from the vacuole into the apoplast during infection. SlChi2 is not modified by $C$. fulvum and the fungus is expected to protect itself against deleterious effects of this enzyme by secretion of the chitinbinding effector protein CfAvr4 (de Wit et al. 2012; Stergiopoulos et al. 2010; van den Burg et al. 2006). In contrast, after inoculation of tomato roots with $F$. oxysporum, the extracellular CBD chitinase

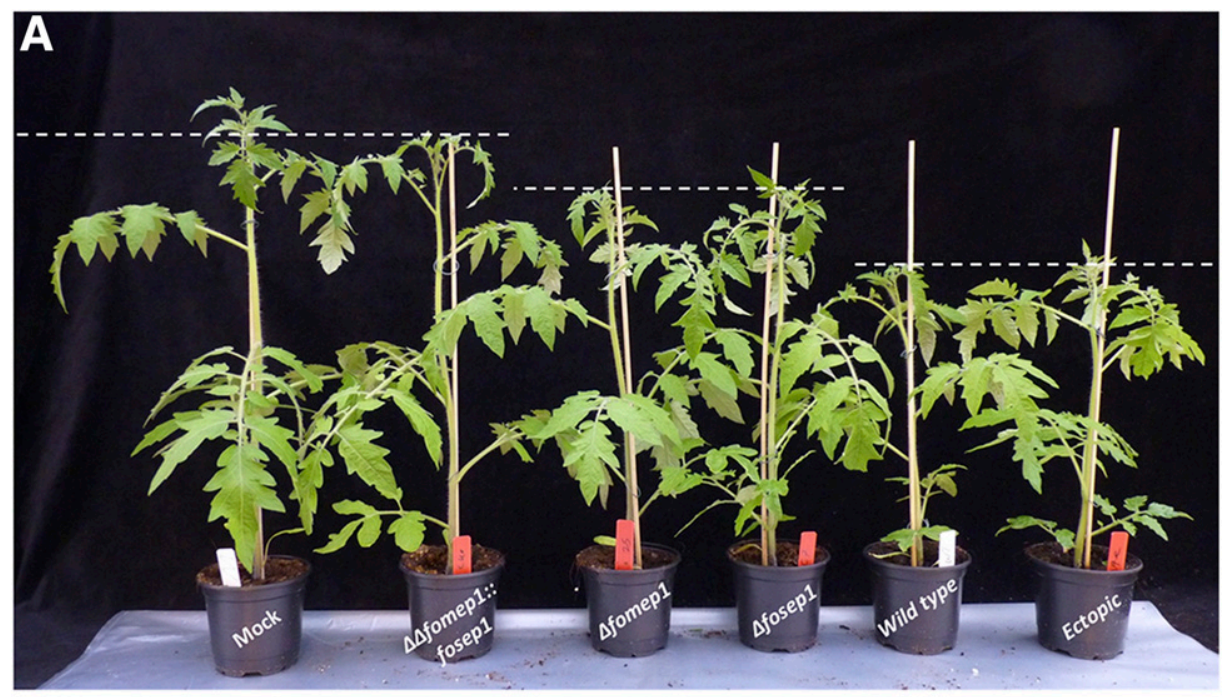

B

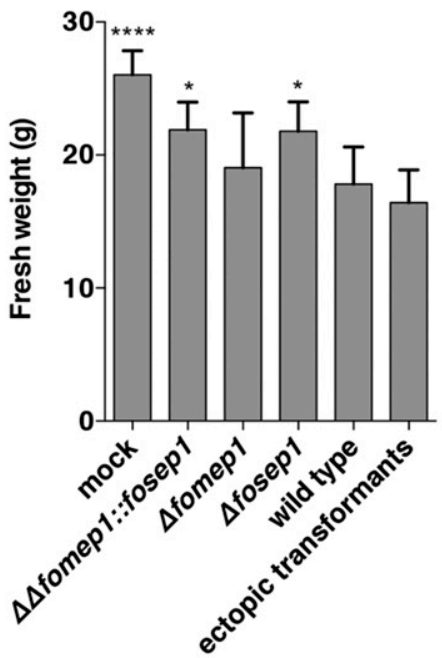

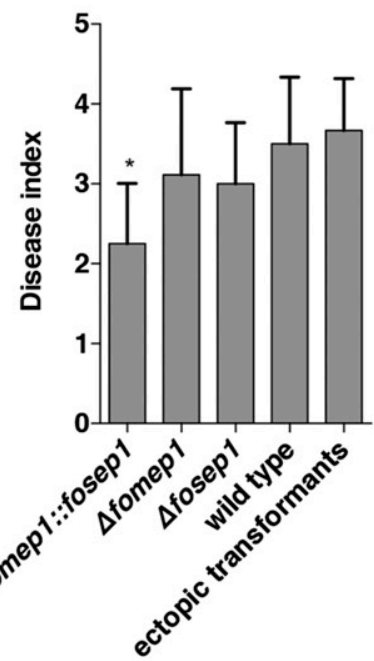

Fig. 6. Synergistic action of a serine and metalloprotease from Fusarium oxysporum $f$. sp. lycopersici is required for full virulence on tomato. A, A representative picture showing MM-Cf-0 tomato plants 4 weeks after inoculation with $F$. oxysporum f. sp. lycopersici $(F$. oxysporum) wild type, ectopic transformants, single-, and double-deletion mutants of FoMepl and FoSepl ( $\Delta$ fomepl\#1, $\Delta$ fosepl\#1, $\Delta \Delta$ fomep1::fosepl\#2). Mock-inoculated plants serve as negative control. B, Fresh weight of upper parts and the disease index of inoculated plants is presented as the average (and standard deviation) of three different plants from two to three independent strains. Results for $\Delta$ fomepl-ectopic and $\Delta$ fosepl-ectopic transformants are presented as ectopic transformants. A twoway analysis of variance with a posthoc Dunnett's multiple comparisons test was performed. Black asterisks indicate significant differences compared with wild type (* indicates $P$ value $<0.5$; ****, $P$ value $<0.0001$ ). 
S1Chi13 is strongly induced at early stages of infection when the fungus colonizes the cortical and vascular tissues. However, SlChi13 could not be detected in xylem sap by mass spectrometry. This might be due to its local accumulation, as reported for spruce seedlings infected by Rhizoctonia spp. (Benhamou et al. 1990; Nagy and Fossdal 2013). Our finding that $F$. oxysporum is able to cleave SIChi1 and SlChi13 is consistent with proteolytic cleavage of plant chitinases as an alternative to secretion of chitin-binding effector proteins. In addition to $F$. oxysporum, another vascular pathogen, $V$. dahliae, and a necrotrophic pathogen, $B$. cinerea, all lacking functional orthologs of the CfAvr4 gene, seem to employ the same strategy, because they were also able to modify the extracellular CBD chitinases SIChi1 and SlChi13 but not the vacuolar CBD chitinases SlChi2 and SlChi4. A deletion mutant of aspartic protease 8 (Bcap8), which encodes the major secreted protease of B. cinerea (ten Have et al. 2010), showed similar chitinase cleavage activity to wild-type $B$. cinerea, meaning that Bcap8 is not responsible for the cleavage of CBD chitinases (results not presented). Homologs of FoMepl and FoSepl genes exist in the genome of $V$. dahliae, but the genome of $B$. cinerea contains only one homolog of FoSepl. We did not further attempt to identify the enzymes responsible for $\mathrm{CBD}$ chitinase modification in these two fungi. Other pathogens like A. solani, A. arborescens, and F. solani did not cleave any of these CBD chitinases, and it remains unknown how they deal with deleterious effects of plant chitinases. However, it has been previously shown that macroconidia of $F$. solani secrete proteases that modify extracellular CBD chitinases (Sela-Buurlage 1996). It is likely that growth of the different fungi on autoclaved tomato leaves did not induce the expression of the corresponding protease in $F$. solani and, possibly, also not in Alternaria species.

The metalloprotease FoMep1 of $F$. oxysporum is the ortholog of the fungalysin metalloprotease of $F$. verticillioides, which infects maize (Naumann et al. 2011). Fungalysin from $F$. verticilloides could completely modify class IV chitinase ChitA from maize, while FoMep1 could only partly modify class IV chitinase SIChi13 from tomato. Complete cleavage of the CBD from SlChi13 was only achieved by synergistic action of FoMep1 and FoSep1 in F. oxysporum. Both proteases were also required for complete modification of the class I chitinase SlChil. A similar enzyme from $F$. solani was suggested to cleave class I chitinase Chi-I from tobacco (Sela-Buurlage 1996). In this fungus and in F. verticillioides, the cleavage site was identified in the hinge between the CBD and the catalytic domain of targeted chitinases. In our study, we found that only synergistic action between metalloprotease FoMep1 and serine protease FoSep1 could cleave the CBD domain of SIChi1 and SlChi13. Synergistic action of proteases has been previously suggested to cleave target proteins (McGowan 2013). We do not know the specificity of FoMep1 and FoSep1, but their synergistic action results in cleavage of class I chitinase SlChil and class IV S1Chi13 at different locations of the N-terminus. It is likely that they act sequentially.

Both $F$. oxysporum and $F$. verticillioides comprise orthologous genes FoMepl and FoSepl in their genomes. In addition, $F$. oxysporum is able to truncate maize ChitA and ChitB (Naumann and Wicklow 2013) and, similarly, F. verticillioides cleavages SlChi1 and SlChi13 chitinases (results not presented), suggesting a similar mechanism involved in both fungi. However, the effects of fungalysin of $F$. verticilloides on antifungal activity of class IV chitinase ChitA from maize and the effects on virulence have never been reported. In our study we could show that antifungal activity of cleaved chitinases was significantly reduced, demonstrating the importance of the CBD in this activity, as also reported previously (Iseli et al. 1993; Suarez et al. 2001). Removal of the CBD also decreased chitinase activity on insoluble chitin azure as a substrate, which is likely due to a decreased affinity for the substrate. The identified proteases did not modify the CBD chitinase
SlChi2 and, consequently, its chitinase and antifungal activity was not changed after incubation with protein extract from F. oxysporum. However, SlChi2 is not induced during infection by $F$. oxysporum, suggesting that this fungus does not need to protect itself against this chitinase. This observation also argues in favor of coevolution between plant chitinases and pathogen proteases. It is expected that CBD chitinases from different hosts exhibit antifungal activity and their cleavage by proteases from host-adapted pathogenic fungi will result in loss of antifungal activity and increase in virulence.

Processing of chitinase was shown to be correlated with accumulation of proteolytic activity in plants infected by Fusarium species (Lange et al. 1996; Naumann et al. 2011; Olivieri et al. 2002). Requirement of proteases for virulence were suggested for several fungal pathogens including Magnaporthe poae (Sreedhar et al. 1999), Pyrenopeziza brassicae (Ball et al. 1991), but no experimental evidence for this role has been reported so far. Targeted mutants of $F$. oxysporum (Di Pietro et al. 2001) lacking prt1, encoding a serine protease different from FoSep1 and FoSep2, and trypsin-deficient mutants of Stagonospora nodorum (Bindschedler et al. 2003) and Cochliobolus carbonum (Murphy and Walton 1996) were not affected in their virulence. In our study, single deletion mutants of $F$. oxysporum showed only slightly reduced virulence based on plant growth, but plant colonization was not significantly impaired. In contrast, the doubledeletion mutant $\Delta \Delta$ fomep $1:$ fosep 1 showed a clear reduction in virulence. These observations suggest that both proteases are only components of an arsenal dedicated to infection. In this regard, it is possible that FoSep2 also plays a role in virulence but its effect could not be measured. The difference between singleand double-deletion mutants might be explained by complete modification of both chitinases SlChil and SlChi13. However, we cannot rule out that FeMep1, FoSep1, and FoSep2 in F. oxysporum target other plant proteins, including additional $\mathrm{PR}$ proteins. Indeed, single proteases might target specific plant proteins and synergistic actions of these enzymes might expand the number of plant protein targets.

In summary, data presented in this and previous studies show that plant pathogenic fungi employ different mechanisms to defend themselves against deleterious effects of CBD chitinases. They either secrete a chitin-binding protein that interferes with chitin-binding of CBD chitinases (van den Burg et al. 2006; van Esse et al. 2007) or secrete proteases that cleave CBD chitinases as shown in this study and previous studies (Naumann and Wicklow 2013). There are also examples of plant pathogens that overcome deleterious effects of PR proteins like $\beta$-1,3-glucanases and proteases by secreting inhibitors of those enzymes (Ham et al. 1997; Rooney et al. 2005; Rose et al. 2002; Tian et al. 2005, 2004). Here we show, for the first time, that full cleavage of class I and class IV tomato CBD chitinases requires synergistic action of two proteases that are required for full virulence of F. oxysporum on tomato. Cleavage of the CBD from extracellular CBD chitinases and reduction of their antifungal activity toward F. oxysporum demonstrated the importance of CBD chitinases in basal defense of tomato. A major challenge with functional analysis of fungal proteases is their redundancy, which explains why single protease deletion mutants did not show changes in phenotypes (Bindschedler et al. 2003; Murphy and Walton 1996). Our study suggests that it is important to investigate synergistic actions of additional secreted proteases of plant pathogens to eventually show their possible roles in virulence.

\section{MATERIALS AND METHODS}

Plant and fungal materials.

The susceptible tomato cultivar Money Maker Cf-0 (MM-Cf-0) was used for all in planta studies, including expression profiling, 
proteomics of foliar apoplastic fluid and xylem sap, and virulence assays. Tomato plants were grown in a greenhouse at $70 \%$ relative humidity, 23 to $25^{\circ} \mathrm{C}$ during daytime and 19 to $21^{\circ} \mathrm{C}$ at night, with a 16-h-light and 8-h-dark regime, and $100 \mathrm{~W} \mathrm{~m}^{-2}$ of supplemental light when the sunlight influx intensity was less than $150 \mathrm{~W} \mathrm{~m}^{-2}$. The fungal strains Alternaria solani (CBS 347.79), Alternaria arborescens (CBS 102605), and Fusarium solani (CBS 835.85) were obtained from CBS-KNAW Fungal Biodiversity Centre, Utrecht, The Netherlands. Strains of Cladosporium fulvum (R97, race 0, WU-CBS131901), Verticillium dahliae (VdLs17, race 1), Botrytis cinerea (B05.10), and Fusarium oxysporum f. sp. lycopersici (strain 4287, VCG 0030) were present in the $-80^{\circ} \mathrm{C}$ glycerol stock of our laboratory.

\section{Virulence assays.}

Inoculation of tomato cultivar MM-Cf- 0 with $C$. fulvum was performed as previously described (Ökmen et al. 2013). Fungal spore suspensions calibrated at $10^{6}$ spores per milliliter were sprayed on the abaxial side of tomato leaves. Leaf samples were collected at different dpi for further studies. For virulence assays with $F$. oxysporum, roots of 10-day-old MM-Cf-0 tomato seedlings were dipped into a spore suspension of this fungus (calibrated at $10^{7}$ spores per milliliter) for $1 \mathrm{~min}$ and were then planted into $13-\mathrm{cm}^{2}$ pots. Plant height, disease index, and fresh weight of upper part of plants were analyzed 4 weeks after inoculation, following a previously described method (Michielse et al. 2009). Disease index was measured as follows. A slice of the hypocotyl was cut $1 \mathrm{~cm}$ above ground level and the number of brown vessels was counted, representing the disease index. Virulence assays for single- and double-deletion mutants were performed in a similar way as described for the wild type with three biological replications.

\section{Genome mining of tomato chitinases.}

Amino acid sequences of plant chitinases belonging to each class were retrieved from the National Center for Biotechnology Information website and were used as query sequences for tblastn searches against the tomato genome (Solgenomics Network). Furthermore, InterPro domains corresponding to different classes of plant chitinases (Supplementary Table S2) were used for further genome mining. For each predicted gene potentially encoding a chitinase, signal peptide and pfam domains were predicted using the SignalP 4.1 server (Petersen et al. 2011) and pfam database (Finn et al. 2014), respectively. Domains, active sites, and catalytic residues were predicted for tomato chitinases based on similarity to previously described chitinases. For phylogenetic analysis, sequences of each class were aligned using Muscle (Edgar 2004). Poorly aligned positions were removed using the Gblock server with less stringent parameters settings (Talavera and Castresana 2007). The curated alignments were used to build maximum likelihood phylogenic trees (JTT amino acid substitution model, four categories of gamma distributed substitution rates, using all sites and 500 bootstrap replications) with MEGA 5.1 (Tamura et al. 2011).

\section{Expression analysis of tomato CBD chitinases.}

Expression of tomato CBD chitinases was studied in leaves and roots of MM-Cf-0 tomato plants. Inoculations were performed with $C$. fulvum and $F$. oxysporum as described above. Leaf samples were collected at 0 (healthy plant), 4, 6, 8, 10, and 12 dpi with $C$. fulvum and were immediately frozen in liquid nitrogen. Root samples were collected at 0 (healthy plant), 4, 8, 12 , and 20 dpi with $F$. oxysporum, were properly washed in water, and were immediately frozen in liquid nitrogen. Total RNA was isolated from fully ground samples, using the Quick-RNA miniprep kit (Zymo Research) as provided by the company. RNA concentration and integrity was checked with a NanoDrop 1000 spectrophotometer (Thermo Scientific) and on $1 \%$ agarose gels, respectively. For each sample, $1 \mu \mathrm{g}$ of total RNA was used for cDNA synthesis, using the First-Strand cDNA synthesis kit (Promega) according to manufacturer's instructions. Primer pairs for tomato chitinase genes (Supplementary Table S3) were designed with Primer3 Plus (Untergasser et al. 2007), and their efficiency and specificity were determined with a dilution series of genomic DNA of MM-Cf-0. Quantitative realtime polymerase chain reaction (qrtPCR) was performed using the 7300 system (Applied Biosystems). Each reaction consisted of $25 \mu \mathrm{l}$, containing $12.5 \mu \mathrm{l}$ of Sensimix (Bioline), $1 \mu \mathrm{l}$ of each forward and reverse primer $(7.5 \mu \mathrm{M}), 1 \mu \mathrm{l}$ of $10 \times$ diluted template cDNA, and $9.5 \mu \mathrm{l}$ of double-distilled water. The thermal profile included an initial $95^{\circ} \mathrm{C}$ denaturation step for $10 \mathrm{~min}$, followed by denaturation for $15 \mathrm{~s}$ at $95^{\circ} \mathrm{C}$ and annealing and extension for $45 \mathrm{~s}$ at $60^{\circ} \mathrm{C}$ for 40 cycles. A previously designed primer pair was used to amplify the reference gene LeTub (accession: DQ205342) (Aimé et al. 2013), which allowed us to normalize the expression of other genes. Results were analyzed using the $\mathrm{E}^{-\Delta \mathrm{Ct}}$ method (Livak and Schmittgen 2001). Experiments included three biological replications.

\section{Isolation of apoplastic fluids and xylem sap.}

Apoplastic fluids were isolated from MM-Cf-0 inoculated with C. fulvum at $12 \mathrm{dpi}$, using a previously described method (de Wit and Spikman 1982). Apoplastic fluids were cleared by centrifugation $(12,000 \times g, 20 \mathrm{~min})$ at $4^{\circ} \mathrm{C}$ and were concentrated three times using 1-kDa-cutoff Amicon filters. For xylem sap isolation, 10 plants of MM-Cf-0 were inoculated with $F$. oxysporum, and 5 weeks later, stems were cut off at $2 \mathrm{~cm}$ above ground level. Xylem sap was harvested using a previously described method (Rep et al. 2002). Xylem sap $(50 \mathrm{ml})$ was cleared by centrifugation $(12,000 \times g, 20 \mathrm{~min})$ at $4{ }^{\circ} \mathrm{C}$ and was dialyzed against $10 \mathrm{mM}$ sodium acetate $\mathrm{pH} 5.2$ buffer, using standard dialysis membrane (Spectrum Labs) cutoff of $3.5 \mathrm{kDa}$. The sample was then freeze-dried and dissolved in 0.5 mlof $10 \mathrm{mM}$ sodium acetate $\mathrm{pH} 5.2$ buffer.

\section{Cloning of CBD chitinase genes, yeast transformation, and protein production.}

Coding sequences of the six genes encoding CBD chitinases (SlChi1, SlChi2, SlChi3, SlChi4, SlChi13, and SlChi14) were amplified from cDNA of healthy leaves, using the primer pairs indicated in Supplementary Table S4. Purified PCR fragments were ligated into the $p P I C 9$ expression vector, following the method previously described (Kombrink 2012). Sequence and orientation of insertion was confirmed for each construct. The different expression vectors were then linearized and transformed into the $P$. pastoris GS115 strain (Kombrink 2012).

Three positive transformants of $P$. pastoris for each construct were screened for protein production in small induction flasks, and Western blots were performed with the crude protein culture to select the transformant with the highest protein expression. Only colonies transformed with SlChil, SlChi2, SlChi4, and Slchil3 produced sufficient amounts of the corresponding proteins. This transformant was used for large-scale protein production in a fermenter (Bioflo 3000), as previously described (Kombrink 2012). Yeast culture filtrates were centrifuged $(4,000 \times g, 20 \mathrm{~min})$. Supernatants were retrieved and centrifuged again $(12,000 \times g, 20 \mathrm{~min})$ at $4^{\circ} \mathrm{C}$. Cell-free supernatants were concentrated using a 10kDa cutoff filter (Pall Nanosep) to $50 \mathrm{ml}$ and were run on a $10-\mathrm{ml}$ Ni-NTA column (Qiagen) at $4^{\circ} \mathrm{C}$. The column was washed with $20 \mathrm{ml}$ of washing buffer $(50 \mathrm{mM}$ $\mathrm{NaH}_{2} \mathrm{PO}_{4}, \mathrm{pH} 8,300 \mathrm{mM} \mathrm{NaCl}$, and $10 \mathrm{mM}$ imidazole), and proteins were eluted with $20 \mathrm{ml}$ of elution buffer $(50 \mathrm{mM}$ $\mathrm{NaH}_{2} \mathrm{PO}_{4}, \mathrm{pH} 8,300 \mathrm{mM} \mathrm{NaCl}$, and $250 \mathrm{mM}$ imidazole). Collected fractions containing the protein of interest were combined 
and dialyzed against $10 \mathrm{mM}$ sodium acetate $\mathrm{pH} 5.2$ buffer, were concentrated using 3-kDa Amicon filters, and were adjusted to a concentration of $1 \mathrm{mg} / \mathrm{ml}$.

\section{Preparation and fractionation}

\section{of fungal secreted protein extracts.}

All fungal species were grown on $1 \%$ Oxoid potato dextrose agar (PDA) plates containing $100 \mu \mathrm{g}$ of streptomycin sulfate salt per milliliter (Sigma-Aldrich). Spores were harvested from PDA plates using sterile water for all fungi, apart from $F$. oxysporum and $F$. solani. For these two fungi, $20 \mathrm{ml}$ of Difco potato dextrose broth (PDB) liquid medium containing $100 \mu \mathrm{g}$ of streptomycin sulfate salt per milliliter (Sigma-Aldrich) was inoculated with a mycelium plug taken from PDA plates and was incubated in an orbital shaker incubator at $22^{\circ} \mathrm{C}$ and $200 \mathrm{rpm}$ for 3 days. All fungal mycelia were filtered out using Miracloth (Calbiochem) and, subsequently, spores were collected by centrifugation at $3,700 \times g$ for $15 \mathrm{~min}$, were resuspended in sterile water, and were adjusted at $10^{6}$ spores $/ \mathrm{ml}$. Erlenmeyer flasks containing $25 \mathrm{~g}$ of fresh leaves from 4-week-old susceptible MM-Cf-0 tomato plants were autoclaved (15 p.s.i., $30 \mathrm{~min}$ ), were inoculated with $3 \mathrm{ml}$ of calibrated spore suspensions, and were incubated as a still culture for 7 days at $22^{\circ} \mathrm{C}$. Secreted proteins were isolated using a previously described method (Naumann et al. 2011). Briefly, $5 \mathrm{~g}$ of inoculated autoclaved tomato leaves were incubated with $5 \mathrm{ml}$ of extraction buffer $(50 \mathrm{mM}$ sodium acetate, pH 5.2, 1 mM EDTA, 2 mM PMSF, 2 mM ascorbic acid) at $4^{\circ} \mathrm{C}$ for $30 \mathrm{~min}$. The mixture was centrifuged at $4,000 \times g$ for $5 \mathrm{~min}$ at $4^{\circ} \mathrm{C}$, and supernatants were centrifuged again at $12,000 \times g$ for $20 \mathrm{~min}$ at $4^{\circ} \mathrm{C}$. The protein extracts were then diluted to a concentration of $1 \mathrm{mg} / \mathrm{ml}$. Prior to fractionation, the $100-\mathrm{ml}$ protein extract isolated from the $\Delta$ fomepl deletion mutant was concentrated using a 3-kDa cutoff filter (Pall Nanosep). The concentrated fraction of $3 \mathrm{ml}$ was separated on a Superdex G-75 column that had been equilibrated with $50 \mathrm{mM}$ Tris- $\mathrm{HCl}$, $\mathrm{pH} 7.5$, running buffer. The column flow rate was $1 \mathrm{ml} / \mathrm{min}$ and 30 fractions of $2 \mathrm{ml}$ were collected, freeze-dried, and dissolved in $200 \mu \mathrm{l}$ of $10 \mathrm{mM}$ sodium acetate, $\mathrm{pH}$ 5.2. Fractions were stored at $-20^{\circ} \mathrm{C}$ for further analysis.

\section{Chitinase modifying assay.}

A chitinase modifying assay was performed using a previously described method (Naumann et al. 2011). Each reaction consisted of $10 \mu \mathrm{l}$ total volume containing $5 \mu \mathrm{g}$ of purified tomato chitinase and $2 \mu \mathrm{g}$ of fungal secreted protein extract in $50 \mathrm{mM}$ sodium acetate buffer, $\mathrm{pH} 5.2$. Reactions were incubated for $20 \mathrm{~h}$ at $25^{\circ} \mathrm{C}$ and were stopped by adding SDS-PAGE loading buffer and a heat treatment of $5 \mathrm{~min}$ at $95^{\circ} \mathrm{C}$. Proteins in the reaction mixture were analyzed by $16 \%$ tricine SDS-PAGE. To identify fractions containing chitinase-modifying proteases, similar chitinase modifying assays were performed, using fractionated protein extracts obtained from deletion mutants of the fungalysin metalloprotease gene (FOXG_16612) of $F$. oxysporum. In each reaction volume of $10 \mu \mathrm{l}, 10 \mu \mathrm{g}$ of purified tomato chitinase SlChil was incubated with $1 \mu \mathrm{l}$ of each fraction in $50 \mathrm{mM}$ sodium acetate buffer, $\mathrm{pH}$ 5.2, and was analyzed as described above.

\section{Mass spectrometry analysis.}

To determine the cleavage site in the targeted extracellular tomato CBD chitinases, SlChil and SlChi13 were incubated with protein extracts of $F$. oxysporum, as described in the chitinase modifying assay section. Extract $(10 \mu \mathrm{l})$ with $3.5 \mu \mathrm{l}$ of SDS gel loading buffer was boiled for 5 min and was run on a $16 \%$ tricine SDS-PAGE gel. Intact and processed SlChi1 and SIChi13 were excised from the tricine SDS-PAGE gel and were cut into cubes of $1 \mathrm{~mm}^{3}$. Proteins were reduced with $50 \mathrm{mM}$ dithiothreitol dissolved into $50 \mathrm{mM}$ ammonium bicarbonate, were carboxamidomethylated with $100 \mathrm{mM}$ iodoacetamide in $50 \mathrm{mM}$ ammonium bicarbonate, and were digested by adding $25 \mu \mathrm{l}$ of $10-\mathrm{ng} / \mu \mathrm{l}$ sequencing grade trypsin or chymotrypsin in $50 \mathrm{mM}$ ammonium bicarbonate. Gel pieces were washed with water in between each step. Peptide samples were cleared by loading them onto a C18+ Stage tip (Lu et al. 2011), followed by elution.

To identify proteases in the active fractions obtained from fractionation of protein extracts, $10 \mu \mathrm{l}$ of each active fraction were loaded on a $16 \%$ tricine SDS-PAGE gel and five bands were excised and prepared for mass spectrometry analysis by reduction and alkylation of cysteine residues, followed by trypsin or chymotrypsin digestion as described above. Samples were then analyzed by nano-scale (n)LC-MS/MS with a Proxeon EASY nLC connected to a LTQ-Orbitrap XL (Lu et al. 2011) at the Laboratory of Biochemistry of Wageningen University.

LC-MS runs with all MS/MS spectra obtained were analyzed with MaxQuant 1.3.0.5 (Cox and Mann 2008), using default settings for the Andromeda search engine (Cox et al. 2011), except that extra variable modifications were set for de-amidation of $\mathrm{N}$ and Q. The $F$. oxysporum database (4287-FO2) was downloaded from the Broad Institute and the tomato database ITAG2.3 was downloaded from the Solgenomics website. These were used together with a contaminant database that contains sequences of common contaminants, e.g., BSA (P02769, bovin serum albumin precursor), trypsin (P00760, bovin), trypsin (P00761, porcin), chymotrypsin (P00766, bovin), keratin K22E (P35908, human), keratin K1C9 (P35527, human), keratin K2C1 (P04264, human), and keratin K1CI (P35527, human).

The "label-free quantification" as well as the "match between runs" (set to $2 \mathrm{~min}$ ) options were enabled. Using de-amidated peptides was allowed for protein quantification and all other quantification settings were kept default. Filtering and further bioinformatic analysis of the MaxQuant/Andromeda workflow output and the analysis of abundances of the identified proteins were performed with the Perseus 1.3.0.4 module (available in the MaxQuant suite). Peptides and proteins with a false discovery rate of less than $1 \%$ and proteins with at least two identified peptides of which at least one unique and one unmodified were considered as reliable identification. Reversed hits were deleted from the MaxQuant result table.

\section{Chitinase activity assay.}

Insoluble chitin azure was used as substrate to assay chitinase activity. In 2-ml low-protein binding tubes (LoBind tubes, Eppendorf), $1 \mathrm{mg}$ of chitin azure (Sigma) was washed once with $1 \mathrm{ml}$ of potassium-phosphate buffer $(100 \mathrm{mM}, \mathrm{pH} 6.0)$ by brief centrifugation. The washed chitin azure pellet was resuspended in $0.9 \mathrm{ml}$ of the same buffer and was then mixed with purified proteins SlChi1, SlChi2, or SlChi13 at a final concentration of $0.1 \mathrm{mg} / \mathrm{ml}$ and incubated for $20 \mathrm{~h}$ at $37^{\circ} \mathrm{C}$. Reactions were centrifuged at $12,000 \times g$ for $10 \mathrm{~min}$ at room temperature, and the optical density of $0.750 \mathrm{ml}$ of supernatants was measured at $560 \mathrm{~nm}$. Similar chitinase activity assays were performed with SlChi1, SlChi2, and SlChi13 chitinases treated with protein extracts of wild type and protease mutant $(\Delta \Delta$ fomep $1:$ :fosepl) of $F$. oxysporum.

\section{Determination of the antifungal activity of full-length and cleaved chitinases.}

Fungal spores of F. oxysporum were harvested in sterile Milli-Q water as described above, and spore concentration was adjusted to $10^{5}$ spores $/ \mathrm{ml}$. Spore suspension $(10 \mu \mathrm{l})$ was mounted on a microscopy slide and, first, was incubated for $4 \mathrm{~h}$ at room temperature inside a moist covered box. Then, $20 \mu \mathrm{l}$ of noncleaved SlChil or S1Chi13 chitinase (in $10 \mathrm{mM}$ sodium 
acetate, $\mathrm{pH}$ 5.2) was added to the spore suspension at a final concentration of $1 \mu \mathrm{g} / \mu \mathrm{l}$. After $16 \mathrm{~h}$, samples were observed, using a Nikon eclipse 90i microscope controlled by the imaging software NIS-Element AR 2.30. The lengths of about 100 germ tubes were measured. Similar antifungal assays were performed with cleaved SlChil and SlChi13 chitinases. For this purpose, both chitinases were incubated with protein extracts of $F$. oxysporum, as described above, prior to incubation with the spore suspension.

\section{Construction of single- and double-deletion mutants of FoMep1, FoSep1, and FoSep2 protease genes in $F$. oxysporum.}

Gene replacement vectors pR4R3 $\Delta$ fomep1, pR4R3 $\Delta$ fosep1, and $\mathrm{pR} 4 \mathrm{R} 3 \Delta$ sfosep 2 were constructed, using the Multisite Gateway three-fragment vector construction kit (Invitrogen) according to the manufacturer's instructions. Genomic DNA was extracted from $F$. oxysporum mycelium that was grown in PDB for 3 days and frozen in liquid nitrogen, using the DNeasy plant mini kit (Qiagen Benelux bv.) according to the manufacturer's instructions. The upstream (US) and the downstream (DS) regions $(1.4 \mathrm{~kb})$ of FoMepl (FOXG_16612), FoSep1 (FOXG_09801), and FoSep2 (FOXG_01145) were amplified from genomic DNA of F. oxysporum. The PCR reactions were performed using GoTaq DNA polymerase (Promega) and oligonucleotides (Supplementary Table S5) containing the specific overhang sequences AttB4, $A t t B 1 r, A t t B 2 r$, or AttB3, which are recombination sites. The US and DS purified PCR fragments of each gene were introduced into pDONR P4-P1R and pDONR P2R-P3 vectors, respectively. A purified US or DS fragment (70 ng), $1 \mu \mathrm{l}$ of BP clonase II enzyme mix (Invitrogen), and $70 \mathrm{ng}$ of the corresponding $\mathrm{pDONR}$ vector were combined in a total volume of $5 \mu \mathrm{l}$. Reactions were incubated overnight at $25^{\circ} \mathrm{C}$ and were used to transform DH5 $\alpha$ Escherichia coli cells by heat-shock treatment. The three replacement vectors were obtained performing LR reactions that contained $70 \mathrm{ng}$ of pDONR P4-P1R_US, $70 \mathrm{ng}$ of pDONR P2R-P_DS, $70 \mathrm{ng}$ of p221_GFP_HYG (containing the green fluorescent protein and hygromycin-resistance genes) (Ökmen et al. 2013), $70 \mathrm{ng}$ of pDESTTMR4-R3 destination vector, and $1 \mu \mathrm{l}$ of LR clonase II enzyme mix (Invitrogen) in a total volume of $5 \mu$ l. Reactions were incubated overnight at $25^{\circ} \mathrm{C}$ and were subsequently transformed into $\mathrm{DH} 5 \alpha$ E. coli. To generate double-knockout mutants, vector pRM254 (Mehrabi et al. 2015), containing GFP and the geneticinresistance gene, was used. The replacement vectors were obtained performing LR reactions using pDONR P4-P1R_US (carrying upstream fragments of FoSepl or FoSep2), pDONR P2R-P_DS (carrying downstream fragments of FoSep1 or FoSep2), pRM254, and pDEST R4-R3 destination vector. The correct orientation of fragments in the final constructs was confirmed by PCR and sequencing. The gene replacement vectors were introduced into Agrobacterium tumefaciens AGL1 cells by electroporation. Agrobacterium tumefaciens-mediated transformation of wild-type strain 4287 and single-deletion mutants of $F$. oxysporum was performed using a method described before (Ökmen et al. 2013). Transformants were selected on PDA plates supplemented with $100 \mu \mathrm{g}$ of hygromycin or $150 \mu \mathrm{g}$ of geneticin per milliliter. Stable transformants were selected by growing them on selective PDA plates, followed by a new culture on nonselective plates. Deletion mutants were screened and characterized by PCR and qrtPCR (Supplementary Table S6).

\section{ACKNOWLEDGMENTS}

We are grateful for the financial assistance provided by the Ministry of Science, Research and Technology (MSRT) of Iran and Wageningen University (to M. K. Jashni) and Grant-in-Aid for Scientific Research, KAKENHI (to Y. Iida).

\section{LITERATURE CITED}

Aimé, S., Alabouvette, C., Steinberg, C., and Olivain, C. 2013. The endophytic strain Fusarium oxysporum Fo47: A good candidate for priming the defense responses in tomato roots. Mol. Plant-Microbe Interact. 26:918-926.

Arlorio, M., Ludwig, A., Boller, T., and Bonfante, P. 1992. Inhibition of fungal growth by plant chitinases and $\beta$-1,3-glucanases. Protoplasma 171:34-43.

Balasubramanian, V., Vashisht, D., Cletus, J., and Sakthivel, N. 2012. Plant $\beta$-1,3-glucanases: Their biological functions and transgenic expression against phytopathogenic fungi. Biotechnol. Lett. 34:1983-1990.

Ball, A. M., Ashby, A. M., Daniels, M. J., Ingram, D. S., and Johnstone, K. 1991. Evidence for the requirement of extracellular protease in the pathogenic interaction of Pyrenopeziza brassicae with oilseed rape. Physiol. Mol. Plant Pathol. 38:147-161.

Benhamou, N., Joosten, M. H. A. J., and de Wit, P. J. G. M. 1990 Subcellular localization of chitinase and of its potential substrate in tomato root tissues infected by Fusarium oxysporum f. sp. radicislycopersici. Plant Physiol. 92:1108-1120.

Bindschedler, L. V., Sanchez, P., Dunn, S., Mikan, J., Thangavelu, M., Clarkson, J. M., and Cooper, R. M. 2003. Deletion of the SNP1 trypsin protease from Stagonospora nodorum reveals another major protease expressed during infection. Fungal Genet. Biol. 38:43-53.

Cletus, J., Balasubramanian, V., Vashisht, D., and Sakthivel, N. 2013. Transgenic expression of plant chitinases to enhance disease resistance. Biotechnol. Lett. 35:1719-1732.

Cota, I. E., Troncoso-Rojas, R., Sotelo-Mundo, R., Sánchez-Estrada, A., and Tiznado-Hernández, M. E. 2007. Chitinase and $\beta$-1,3-glucanase enzymatic activities in response to infection by Alternaria alternate evaluated in two stages of development in different tomato fruit varieties. Sci. Hortic. (Amsterdam) 112:42-50.

Cox, J., and Mann, M. 2008. MaxQuant enables high peptide identification rates, individualized p.p.b.-range mass accuracies and proteome-wide protein quantification. Nat. Biotechnol. 26:1367-1372.

Cox, J., Neuhauser, N., Michalski, A., Scheltema, R. A., Olsen, J. V., and Mann, M. 2011. Andromeda: A peptide search engine integrated into the MaxQuant environment. J. Proteome Res. 10:1794-1805.

Danhash, N., Wagemakers, C. A., van Kan, J. A., and de Wit, P. J. 1993. Molecular characterization of four chitinase cDNAs obtained from Cladosporium fulvum-infected tomato. Plant Mol. Biol. 22:1017-1029.

Dana, M. de las M., Pintor-Toro, J. A., and Cubero, B. 2006. Transgenic tobacco plants overexpressing chitinases of fungal origin show enhanced resistance to biotic and abiotic stress agents. Plant Physiol. 142:722-730.

de Wit, P. G. M., and Spikman, G. 1982. Evidence for the occurence of race and cultivar-specific elicitors of necrosis in intercellular fluids of compatible interactions of Cladosporium fulvum and tomato. Physiol. Plant Pathol. 21:1-8

de Wit, P. J. G. M., van der Burgt, A., Ökmen, B., Stergiopoulos, I., AbdElsalam, K. A., Aerts, A. L., Bahkali, A. H., Beenen, H. G., Chettri, P., Cox, M. P., Datema, E., de Vries, R. P., Dhillon, B., Ganley, A. R., Griffiths, S. A., Guo, Y., Hamelin, R. C., Henrissat, B., Kabir, M. S., Jashni, M. K., Kema, G., Klaubauf, S., Lapidus, A., Levasseur, A., Lindquist, E., Mehrabi, R., Ohm, R. A., Owen, T. J., Salamov, A., Schwelm, A., Schijlen, E., Sun, H., van den Burg, H. A., van Ham, R. C. H. J., Zhang, S., Goodwin, S. B., Grigoriev, I. V., Collemare, J., and Bradshaw, R. E. 2012. The genomes of the fungal plant pathogens Cladosporium fulvum and Dothistroma septosporum reveal adaptation to different hosts and lifestyles but also signatures of common ancestry. PLoS Genet. 8:e1003088.

Di Pietro, A., Huertas-González, M. D., Gutierrez-Corona, J. F., MartínezCadena, G., Méglecz, E., and Roncero, M. I. G. 2001. Molecular characterization of a subtilase from the vascular wilt fungus Fusarium oxysporum. Mol. Plant-Microbe Interact. 14:653-662.

Edgar, R. C. 2004. MUSCLE: A multiple sequence alignment method with reduced time and space complexity. BMC Bioinformatics 5:113.

Finn, R. D., Bateman, A., Clements, J., Coggill, P., Eberhardt, R. Y., Eddy, S. R., Heger, A., Hetherington, K., Holm, L., Mistry, J., Sonnhammer, E. L. L., Tate, J., and Punta, M. 2014. Pfam: The protein families database. Nucleic Acids Res. 42:D222-D230.

Godoy, A. V., Olivieri, F. P., and Casalongue, C. A. 1996. Induction of hydrolytic enzymes and antifungal in vitro activity in S. tuberosum subsp. andigena after infection with Fusarium solani f. sp. eumartii. Potato Res. 39:259-266.

Grover, A. 2012. Plant chitinases: Genetic diversity and physiological roles. Crit. Rev. Plant Sci. 31:57-73.

Ham, K. S., Wu, S. C., Darvill, A. G., and Albersheim, P. 1997. Fungal pathogens secrete an inhibitor protein that distinguishes isoforms 
of plant pathogenesis-related endo- $\beta-1,3$-glucanases. Plant J. 11 : 169-179.

Hamid, R., Khan, M. A., Ahmad, M., Ahmad, M. M., Abdin, M. Z., Musarrat, J., and Javed, S. 2013. Chitinases: An update. J. Pharm. Bioallied Sci. 5:21-29.

Houterman, P. M., Speijer, D., Dekker, H. L., DE Koster, C. G., Cornelissen, B. J. C., and Rep, M. 2007. The mixed xylem sap proteome of Fusarium oxysporum-infected tomato plants. Mol. Plant Pathol. 8:215-221.

Iqbal, M. M., Nazir, F., Ali, S., Asif, M. A., Zafar, Y., Iqbal, J., and Ali, G. M. 2012. Over expression of rice chitinase gene in transgenic peanut (Arachis hypogaea L.) improves resistance against leaf spot. Mol. Biotechnol. 50:129-136.

Iseli, B., Boller, T., and Neuhaus, J. M. 1993. The N-terminal cysteine-rich domain of tobacco class I chitinase is essential for chitin binding but not for catalytic or antifungal activity. Plant Physiol. 103:221-226.

Jongedijk, E., Tigelaar, H., Van Roekel, J. S., Bres-Vloemans, S. A., Dekker, I., van den Elzen, P. J., Cornelissen, B. J., and Melchers, L. S. 1995. Synergistic activity of chitinases and $\beta$-1,3-glucanases enhances fungal resistance in transgenic tomato plants. Euphytica 85:173-180.

Joosten, M. H. A. J., and De Wit, P. J. G. M. 1989. Identification of several pathogenesis-related proteins in tomato leaves inoculated with Cladosporium fulvum (syn. Fulvia fulva) as 1,3- $\beta$-glucanases and chitinases. Plant Physiol. 89:945-951.

Joosten, M. H. A. J., Verbakel, H., Nettekoven, M., Van Leeuwen, J., Van der Vossen, R., and de Wit, P. J. G. M. 1995. The phytopathogenic fungus Cladosporium fulvum is not sensitive to the chitinase and $\beta$-1,3-glucanase defence proteins of its host, tomato. Physiol. Mol. Plant Pathol. 46:45-59.

Kolosova, N., Breuil, C., and Bohlmann, J. 2014. Cloning and characterization of chitinases from interior spruce and lodgepole pine. Phytochemistry 101:32-39.

Kombrink, A. 2012. Heterologous production of fungal effectors in Pichia pastoris. Methods Mol. Biol. 835:209-217.

Lange, J., Mohr, U., Wiemken, A., Boller, T., and Vögeli-Lange, R. 1996. Proteolytic processing of class IV chitinase in the compatible interaction of bean roots with Fusarium solani. Plant Physiol. 111:1135-1144.

Li, H., and Greene, L. H. 2010. Sequence and structural analysis of the chitinase insertion domain reveals two conserved motifs involved in chitin-binding. PLoS ONE 5:e8654.

Livak, K. J., and Schmittgen, T. D. 2001. Analysis of relative gene expression data using real-time quantitative PCR and the $2^{-\Delta \Delta} \mathrm{C}(\mathrm{T})$ method. Methods 25:402-408.

Lu, J., Boeren, S., de Vries, S. C., van Valenberg, H. J. F., Vervoort, J., and Hettinga, K. 2011. Filter-aided sample preparation with dimethyl labeling to identify and quantify milk fat globule membrane proteins. J. Proteomics 75:34-43.

Lu, S.-W., Kroken, S., Lee, B.-N., Robbertse, B., Churchill, A. C. L., Yoder, O. C., and Turgeon, B. G. 2003. A novel class of gene controlling virulence in plant pathogenic ascomycete fungi. Proc. Natl. Acad. Sci. U.S.A. 100:5980-5985.

Mauch, F., Mauch-Mani, B., and Boller, T. 1988. Antifungal hydrolases in pea tissue. II. Inhibition of fungal growth by combinations of chitinase and $\beta$-1,3-glucanase. Plant Physiol. 88:936-942.

Maximova, S. N., Marelli, J.-P., Young, A., Pishak, S., Verica, J. A., and Guiltinan, M. J. 2006. Over-expression of a cacao class I chitinase gene in Theobroma cacao L. enhances resistance against the pathogen, Colletotrichum gloeosporioides. Planta 224:740-749.

McGowan, S. 2013. Working in concert: The metalloaminopeptidases from Plasmodium falciparum. Curr. Opin. Struct. Biol. 23:828-835.

Mehrabi, R., Mirzadi-Gohari, A., Ferreira da Silva, G., Steinberg, G., and Kema, G. H. J., and de Wit, P. J. G. M. 2015. Flexible gateway constructs for functional analyses of genes in plant pathogenic fungi. Fungal Genet. Biol. 79:186-192.

Michielse, C. B., van Wijk, R., Reijnen, L., Cornelissen, B. J., and Rep, M. 2009. Insight into the molecular requirements for pathogenicity of Fusarium oxysporum f. sp. lycopersici through large-scale insertional mutagenesis. Genome Biol. 10:R4.

Murphy, J. M., and Walton, J. D. 1996. Three extracellular proteases from Cochliobolus carbonum: Cloning and targeted disruption of ALP1. Mol. Plant-Microbe Interact. 9:290-297.

Nagy, N. E., and Fossdal, C. G. 2013. Host responses in Norway spruce roots induced to the pathogen Ceratocystis polonica are evaded or suppressed by the ectomycorrhizal fungus Laccaria bicolor. Plant Biol Stuttg 15:99-110.

Naumann, T. A. 2011. Modification of recombinant maize ChitA chitinase by fungal chitinase-modifying proteins. Mol. Plant Pathol. $12: 365-372$.
Naumann, T. A., and Wicklow, D. T. 2010. Allozyme-specific modification of a maize seed chitinase by a protein secreted by the fungal pathogen Stenocarpella maydis. Phytopathology 100:645-654.

Naumann, T. A., and Wicklow, D. T. 2013. Chitinase modifying proteins from phylogenetically distinct lineages of Brassica pathogens. Physiol. Mol. Plant Pathol. 82:1-9.

Naumann, T. A., Wicklow, D. T., and Kendra, D. F. 2009. Maize seed chitinase is modified by a protein secreted by Bipolaris zeicola. Physiol. Mol. Plant Pathol. 74:134-141.

Naumann, T. A., Wicklow, D. T., and Price, N. P. J. 2011. Identification of a chitinase-modifying protein from Fusarium verticillioides: Truncation of a host resistance protein by a fungalysin metalloprotease. J. Biol. Chem. 286:35358-35366.

Neuhaus, J. M., Sticher, L., Meins, F., Jr., and Boller, T. 1991. A short $\mathrm{C}$-terminal sequence is necessary and sufficient for the targeting of chitinases to the plant vacuole. Proc. Natl. Acad. Sci. U.S.A. 88: 10362-10366.

Ohnuma, T., Numata, T., Osawa, T., Inanaga, H., Okazaki, Y., Shinya, S., Kondo, K., Fukuda, T., and Fukamizo, T. 2012. Crystal structure and chitin oligosaccharide-binding mode of a 'loopful' family GH19 chitinase from rye, Secale cereale, seeds. FEBS (Fed. Eur. Biochem. Soc.) J. 279:3639-3651.

Ohnuma, T., Numata, T., Osawa, T., Mizuhara, M., Lampela, O., Juffer, A. H., Skriver, K., and Fukamizo, T. 2011. A class V chitinase from Arabidopsis thaliana: Gene responses, enzymatic properties, and crystallographic analysis. Planta 234:123-137.

Ökmen, B., Etalo, D. W., Joosten, M. H. A. J., Bouwmeester, H. J., de Vos, R. C. H., Collemare, J., and de Wit, P. J. G. M. 2013. Detoxification of $\alpha$-tomatine by Cladosporium fulvum is required for full virulence on tomato. New Phytol. 198:1203-1214.

Olivieri, F., Eugenia Zanetti, M., Oliva, C. R., Covarrubias, A. A., and Casalongué, C. A. 2002. Characterization of an extracellular serine protease of Fusarium eumartii and its action on pathogenesis related proteins. Eur. J. Plant Pathol. 108:63-72.

Petersen, T. N., Brunak, S., von Heijne, G., and Nielsen, H. 2011. SignalP 4.0: Discriminating signal peptides from transmembrane regions. Nat. Methods 8:785-786.

Rep, M., Dekker, H. L., Vossen, J. H., de Boer, A. D., Houterman, P. M., Speijer, D., Back, J. W., de Koster, C. G., and Cornelissen, B. J. C. 2002. Mass spectrometric identification of isoforms of PR proteins in xylem sap of fungus-infected tomato. Plant Physiol. 130:904-917.

Rooney, H. C. E., Van't Klooster, J. W., van der Hoorn, R. A. L., Joosten, M. H. A. J., Jones, J. D. G., and de Wit, P. J. G. M. 2005. Cladosporium Avr2 inhibits tomato Rcr3 protease required for Cf-2-dependent disease resistance. Science 308:1783-1786.

Rose, J. K. C., Ham, K.-S., Darvill, A. G., and Albersheim, P. 2002. Molecular cloning and characterization of glucanase inhibitor proteins: Coevolution of a counterdefense mechanism by plant pathogens. Plant Cell 14:1329-1345.

Schickler, H., and Chet, I. 1997. Heterologous chitinase gene expression to improve plant defence against phytopathogenic fungi. J. Ind. Microbiol. Biotechnol. 19:196-201.

Sela-Buurlage, M. B. (1996) In vitro sensitivity and tolerance of Fusarium solani towards chitinases and $\beta$-1,3-glucanases. Ph.D. thesis, Wageningen University, The Netherlands.

Sela-Buurlage, M. B., Ponstein, A. S., Bres-Vloemans, S. A., Melchers, L. S., Van Den Elzen, P., and Cornelissen, B. 1993. Only specific tobacco (Nicotiana tabacum) chitinases and $\beta$-1,3-glucanases exhibit antifungal activity. Plant Physiol. 101:857-863.

Sels, J., Mathys, J., De Coninck, B. M. A., Cammue, B. P. A., and De Bolle, M. F. C. 2008. Plant pathogenesis-related (PR) proteins: A focus on PR peptides. Plant Physiol. Biochem. 46:941-950.

Sinha, M., Singh, R. P., Kushwaha, G. S., Iqbal, N., Singh, A., Kaushik, S., Kaur, P., Sharma, S., and Singh, T. P. 2014. Current overview of allergens of plant pathogenesis related protein families. Scientific World Journal 2014:543195.

Sreedhar, L., Kobayashi, D. Y., Bunting, T. E., Hillman, B. I., and Belanger, F. C. 1999. Fungal proteinase expression in the interaction of the plant pathogen Magnaporthe poae with its host. Gene 235:121-129.

Stergiopoulos, I., van den Burg, H. A., Ökmen, B., Beenen, H. G., van Liere, S., Kema, G. H. J., and de Wit, P. J. G. M. 2010. Tomato Cf resistance proteins mediate recognition of cognate homologous effectors from fungi pathogenic on dicots and monocots. Proc. Natl. Acad. Sci. U.S.A. 107:7610-7615.

Suarez, V., Staehelin, C., Arango, R., Holtorf, H., Hofsteenge, J., and Meins, F., Jr. 2001. Substrate specificity and antifungal activity of recombinant tobacco class I chitinases. Plant Mol. Biol. 45:609-618. 
Talavera, G., and Castresana, J. 2007. Improvement of phylogenies after removing divergent and ambiguously aligned blocks from protein sequence alignments. Syst. Biol. 56:564-577.

Tamura, K., Peterson, D., Peterson, N., Stecher, G., Nei, M., and Kumar, S. 2011. MEGA5: Molecular evolutionary genetics analysis using maximum likelihood, evolutionary distance, and maximum parsimony methods. Mol. Biol. Evol. 28:2731-2739.

ten Have, A., Espino, J. J., Dekkers, E., Van Sluyter, S. C., Brito, N., Kay, J., González, C., and van Kan, J. A. L. 2010. The Botrytis cinerea aspartic proteinase family. Fungal Genet. Biol. 47:53-65.

Tian, M., Benedetti, B., and Kamoun, S. 2005. A second Kazal-like protease inhibitor from Phytophthora infestans inhibits and interacts with the apoplastic pathogenesis-related protease P69B of tomato. Plant Physiol. 138:1785-1793.

Tian, M., Huitema, E., Da Cunha, L., Torto-Alalibo, T., and Kamoun, S. 2004. A Kazal-like extracellular serine protease inhibitor from Phytophthora infestans targets the tomato pathogenesis-related protease P69B. J. Biol. Chem. 279:26370-26377.

Truong, N.-H., Park, S.-M., Nishizawa, Y., Watanabe, T., Sasaki, T., and Itoh, Y. 2003. Structure, heterologous expression, and properties of rice (Oryza sativa L.) family 19 chitinases. Biosci. Biotechnol. Biochem. 67: 1063-1070.

Untergasser, A., Nijveen, H., Rao, X., Bisseling, T., Geurts, R., and Leunissen, J. A. M. 2007. Primer3Plus, an enhanced web interface to Primer3. Nucleic Acids Res. 35:W71-W74.

van den Burg, H. A., Harrison, S. J., Joosten, M. H. A. J., Vervoort, J., and de Wit, P. J. G. M. 2006. Cladosporium fulvum Avr4 protects fungal cell walls against hydrolysis by plant chitinases accumulating during infection. Mol. Plant-Microbe Interact. 19:1420-1430.

van Esse, H. P., Bolton, M. D., Stergiopoulos, I., de Wit, P. J. G. M., and Thomma, B. P. H. J. 2007. The chitin-binding Cladosporium fulvum effector protein Avr4 is a virulence factor. Mol. Plant-Microbe Interact. 20:1092-1101.

van Loon, L. C., Rep, M., and Pieterse, C. M. J. 2006. Significance of inducible defense-related proteins in infected plants. Annu. Rev. Phytopathol. 44: $135-162$.

Wu, S. W., Wang, H. W., Yang, Z. D., and Kong, L. R. 2014. Expression comparisons of pathogenesis-related $(P R)$ genes in wheat in response to infection/infestation by Fusarium, Yellow dwarf virus (YDV) aphidtransmitted and hessian fly. J. Integr. Agr. 13:926-936.

Wubben, J. P., Joosten, M. H. A. J. M., Vankan, J. A. L., and de Wit, P. J. G. M. 1992. Subcellular localization of plant chitinases and 1,3beta-glucanases in Cladosporium fulvum (syn. Fulvia fulva)-infected tomato leaves. Physiol. Mol. Plant Pathol. 41:23-32.

Yamagami, T., and Ishiguro, M. 1998. Complete amino acid sequences of chitinase-1 and -2 from bulbs of genus Tulipa. Biosci. Biotechnol. Biochem. 62:1253-1257.

\section{AUTHOR-RECOMMENDED INTERNET RESOURCES}

Broad Institute website: https://www.broadinstitute.org National Center for Biotechnology Information website: www.ncbi.nlm.nih.gov

Solgenomics Network: http://solgenomics.net 